\title{
Competition of mechanisms contributing to the texture formation in metastable austenitic steel under compressive load
}

\author{
C. Ullrich ${ }^{\mathrm{a}, *}$, S. Martin ${ }^{\mathrm{a}}$, C. Schimpf ${ }^{\mathrm{a}}$, H.-G. Brokmeier ${ }^{\mathrm{b}}$, N. Schell ${ }^{\mathrm{c}}$, A. Stark ${ }^{\mathrm{c}}$, D. Rafaja ${ }^{\mathrm{a}}$ \\ ${ }^{a}$ Institute of Materials Science, TU Bergakademie Freiberg, Gustav-Zeuner-Str. 5, 09599 Freiberg, Germany \\ ${ }^{\mathrm{b}}$ Institute of Materials Science and Engineering, Clausthal University of Technology, Agricolastr. 6, 38678 Clausthal-Zellerfeld, Germany \\ ${ }^{\mathrm{c}}$ Helmholtz-Zentrum Geesthacht, Max-Planck-Str. 1, 21502 Geesthacht, Germany
}

\section{A R T I C L E I N F O}

\section{Keywords:}

TRIP/TWIP steels

Synchrotron radiation diffraction

Electron backscatter diffraction

Martensitic transformation

Texture

Variant selection

\begin{abstract}
A B S T R A C T
The interplay of microstructural mechanisms controlling the deformation-induced martensitic phase transformations and the texture formation in all phases of a metastable austenitic Cr-Mn-Ni steel was investigated using in situ synchrotron radiation diffraction under uniaxial compression and ex situ electron backscatter diffraction. With increasing deformation, the originally fully austenitic steel transformed to a mixture of $\gamma$-austenite, $\varepsilon$-martensite and $\alpha$-martensite. The face centred cubic $\gamma$-austenite formed a fibre texture $\{110\}$ with respect to the deformation direction. The texture degree increased progressively with increasing deformation. The hexagonal close packed $\varepsilon$-martensite was preferentially oriented with the reciprocal direction $\{10 \overline{1} 3\}$ along the load axis. The texture degree was nearly independent of the deformation extent. The body centred $\alpha$-martensite formed a mixed texture $\{100\} \&\{111\}$ along the deformation direction. The texture component $\{100\}$ was very strong in the early stages of the $\alpha$-martensite formation, but it deteriorated with increasing deformation. The texture evolution is explained by the competition between the transformation texture, several deformation-induced mechanisms, which are highly sensitive to the local orientation of the grains with respect to the acting force, like the stacking fault formation and martensitic transformation in austenite, and the variant selection in both martensites and the twinning of $\alpha$-martensite.
\end{abstract}

\section{Introduction}

A characteristic property of metastable austenitic steels alloyed with several percent of $\mathrm{Cr}, \mathrm{Mn}$ and $\mathrm{Ni}$ is the combination of high deformability, high strength and high strain hardening [1]. These characteristics are based on the transformation-induced plasticity (TRIP) and/or on the twinning-induced plasticity (TWIP) effects [2-4], and utilized, e.g., for absorption of the deformation energy in construction parts fabricated from the TRIP/TWIP steels $[5,6]$. Regarding the crystal plasticity, the TRIP/TWIP steels show a complex deformation behaviour. It comprises formation and slip of perfect dislocations, their dissociation, formation of stacking faults and twins in the face centred cubic (fcc) $\gamma$-austenite (space group $F m \overline{3} m$ ), and the deformation-induced transformation of faulted $\gamma$-austenite to hexagonal close packed (hcp) $\varepsilon$-martensite (SG $P 6_{3} / m m c$ ) and to body centred cubic (bcc) $\alpha$-martensite (SG $\operatorname{Im} \overline{3} m$ ) [7-12]. The proportions of the active deformation mechanisms are controlled mainly by the stacking fault energy (SFE) of austenite, which depends on the chemical composition of the austenitic steel and on the deformation temperature [13-16]. The deformation of austenitic steels with low SFE $\left(<20 \mathrm{~mJ} / \mathrm{m}^{2}\right)$ starts with the formation and dissociation of perfect dislocations, and proceeds by the formation of stacking faults, by their accumulation in deformation bands and by the transformation of $\gamma$-austenite to $\varepsilon$ - and $\alpha$-martensites [17-20]. The main deformation mechanisms in austenitic steels with high SFE $\left(>20 \mathrm{~mJ} / \mathrm{m}^{2}\right)$ are the dislocation glide and twinning $[2,8,16]$.

The phase transformation $\gamma \rightarrow \varepsilon$ can be described as a periodic arrangement of stacking faults in deformation bands of austenite, in which the stacking faults are located on every second $\{111\}$ lattice plane [9]. Especially the $\varepsilon$-martensite that is present at the intersections of the deformation bands, which form on the crystallographically equivalent lattice planes $\{111\}$, acts as nucleation site for $\alpha$-martensite [10,21-24]. The similarities in the crystal structures of $\gamma$-austenite and $\varepsilon$ - and $\alpha$-martensites $[19,23]$ lead to the orientation relationships (OR) that were described by Shoji and Nishiyama [25].

\footnotetext{
* Corresponding author.

E-mail address: christiane.ullrich@ww.tu-freiberg.de (C. Ullrich).
} 
$\{111\}_{\gamma}\left\|\{0001\}_{\varepsilon} \&\langle 1 \overline{1} 0\rangle_{\gamma}\right\|\langle 11 \overline{2} 0\rangle_{\varepsilon}$

and by Burgers [26].

$\{0001\}_{\varepsilon}\left\|\{110\}_{\alpha} \&\langle 1 \overline{1} 20\rangle_{\varepsilon}\right\|\langle 1 \overline{1} 1\rangle_{\alpha}$

Consequently, the orientation relationship between $\gamma$-austenite and $\alpha$-martensite corresponds approximately to the Kurdjumov-Sachs (KS) OR [27]:

$\{111\}_{\gamma}\left\|\{110\}_{\alpha} \&\langle 1 \overline{1} 0\rangle_{\gamma}\right\|\langle 1 \overline{1} 1\rangle_{\alpha}$

Under uniaxial deformation via dislocation slip, fcc metals and alloys form typically fibre textures. Under compression, a $\{110\}$ texture dominates that is a result of the grain rotation [28,29]. Regarding the texture formation, metastable austenitic steels show principally the same behaviour as other fcc metals and alloys [30-32]. Furthermore, as the orientation of the austenite grains towards the deformation direction influences the tendency of the stacking fault formation and hence the extent of the deformation-induced martensitic transformation [33-39], the deformation-induced texture formation in austenite affects the activity of the respective deformation mechanisms and finally the local amount of the phase transformations [40-42].

The interaction between the preferred orientation of crystallites and the dominant deformation mechanism was illustrated on several examples in the past. In single-phase austenitic TWIP steels, which were subjected to uniaxial tensile deformation, a $\{111\}$ fibre texture formed. The associated grain rotation facilitates the twinning activity, which, vice versa, intensifies the preferential orientation of crystallites $[37,42,43]$. In TRIP steels, the plastic deformations via dislocation slip and faulting of austenite and via phase transformation $\varepsilon \rightarrow \alpha^{\prime}$ act possibly as competing mechanisms regarding the texture evolution [30,31,44-47]. $\varepsilon$ - and $\alpha$-martensites transformed during the plastic deformation exhibit distinct textures [45,48-50].

Several studies explained the texture formation in martensites by a selective transformation of austenite grains having a specific orientation with respect to the load direction $[31,44,45,48,51,52]$. Other reports considered the variant selection as a crucial reason for the texture formation in deformation-induced $\alpha$-martensite [53-61]. Due to the interplay between the applied stress and the transformation strain, not all crystallographically possible martensite variants, which are expected for the orientation relationships from Eqs. (1) to (3), really develop, as it was confirmed for the martensitic transformation during cooling $[62,63]$. Only the martensite variants were generated, in which the major component of the transformation strain was oriented parallel to the external (tensile) stress. In other words, the martensite variants are preferred, for which the transforming crystallites can expand along the tensile direction $[55,58,61,64,65]$. This kind of the variant selection was evidenced for both martensite phases, $\varepsilon$ and $\alpha[56,65]$.

In this work, the texture formation and the dependence of the texture degree on the deformation state were analysed in all phases of a uniaxially compressed metastable austenitic TRIP steel using in situ synchrotron XRD measurements. This experimental technique becomes more and more popular, mainly because of its huge information content [66-72]. The integral information about the texture development and phase transformations obtained from the synchrotron measurements is complemented by the local orientation relationships obtained from electron backscatter diffraction (EBSD) patterns of selected deformation states. The results of this study show the competition between the deformation and the transformation textures in austenite and in $\varepsilon$ - and $\alpha$-martensites, illustrate the role of the variant selection during the deformation-induced martensitic transformation and contribute to the understanding of the interplay between the individual plastic deformation mechanisms in the austenitic TRIP steels. A consistent model explaining the evolution of the deformation texture in all phases appearing in plastically deformed high-alloy TRIP steels was developed, which is based on the stacking-fault mediated transformation process.

\section{Experimental details}

The metastable austenitic steel under study contained $16 \mathrm{wt} \% \mathrm{Cr}, 7$ $\mathrm{wt} \% \mathrm{Mn}, 3 \mathrm{wt} \% \mathrm{Ni}, 1 \mathrm{wt} \% \mathrm{Si}$ and $0.04 \mathrm{wt} \% \mathrm{C}$ as confirmed using ICP spectrometry, combustion analysis (C) and X-ray fluorescence (Cr, Ni), corresponding to a designation $\mathrm{X} 4 \mathrm{CrMnNi}$ 16-7-3. The SFE of this steel at room temperature is $(8.1 \pm 0.9) \mathrm{mJ} / \mathrm{m}^{2}$ [73]. In order to obtain a finegrained microstructure that is required for statistically reliable XRD texture measurements, the samples for the in situ synchrotron diffraction experiments were produced from atomized powder using spark plasma sintering. These samples had a fully austenitic microstructure with a medium grain size of approx. $5 \mu \mathrm{m}$.

The in situ synchrotron diffraction experiments were conducted at the High-Energy Materials Science (HEMS) beamline P07 (PETRA III/ DESY) at the X-ray energy of $\sim 100 \mathrm{keV}$ in the transmission diffraction geometry. The cylindrical samples (4 mm diameter, $8 \mathrm{~mm}$ height) were uniaxially compressed in a Bähr DIL-805 A/D deformation dilatometer up to the maximum force of $20 \mathrm{kN}$, which corresponds to a technical stress of $1590 \mathrm{MPa}$ and to the (true) compression of $25 \%$. The load applied to the sample was increased between the subsequent diffraction measurements. The experiment was conducted at room temperature. A beam size of $1 \times 1 \mathrm{~mm}^{2}$ was used to cover a large sample volume (approx. $4 \mathrm{~mm}^{3}$ ) and to achieve a good statistical quality of the diffracted intensities. The direction of the primary beam was perpendicular to the loading direction. The diffraction patterns were recorded using a fast $2 \mathrm{D}$ detector (Perkin-Elmer, $2048 \times 2048 \mathrm{px}$ ). The data acquisition time was $1 \mathrm{~s}$ per frame. The distance between the sample and the detector was $1169 \mathrm{~mm}$. In this experimental setup, the maximum accessible magnitude of the diffraction vector $(|\vec{q}|=4 \pi \sin \theta / \lambda)$ is $89 \mathrm{~nm}^{-1}$. The wavelength of the radiation $(0.01235 \mathrm{~nm})$ was verified by diffraction measurement carried out on the $\mathrm{LaB}_{6}$ standard from the National Institute of Standards and Technology (NIST).

Preferred orientations of crystallites in individual phases were determined from the azimuthal distribution of the diffracted intensities [74] using the E-WIMV method [75], which is implemented in the MAUD program [76-78]. As the sample was not rotated around its own axis during the synchrotron radiation diffraction measurement, the texture degrees were determined from the single diffraction images recorded in each deformation step assuming that the preferred orientation of crystallites is rotationally symmetrical around the deformation direction. Still, it must be noted that a high reliability of this approach is only guaranteed, if a sufficiently high number of diffraction lines with different diffraction indices are used for calculation of the orientation distribution function (ODF) $[79,80]$. With $|\vec{q}| \leq 89 \mathrm{~nm}^{-1}$, 8 diffraction lines of austenite (up to 422), 20 diffraction lines of $\varepsilon$-martensite (up to 300 ) and 8 diffraction lines of $\alpha$-martensite (up to 400) were measured. For the sectional integration of the diffraction images, the program Fit2D [81] was utilized. The 2D diffraction rings were integrated over 'cake' sections with the azimuthal extension of $5^{\circ}$, which was a compromise between a good statistical quality of the integrated diffraction data and a good resolution in the orientation space. The integrated data were processed using a Rietveld routine implemented in the MAUD program [76]. The refined parameters were the volume fractions of austenite and $\varepsilon$ - and $\alpha$-martensites, their lattice parameters, the lattice stresses, the crystallite sizes, the microstrains and the degree of the preferred orientation in all phases, and the stacking fault probabilities for austenite and $\varepsilon$-martensite (for details, see [67]).

Local orientation measurements that served as a proof of the variant selection were done using an EBSD analysis in a Zeiss Leo 1530 scanning electron microscope (SEM). The SEM was operated at $20 \mathrm{kV}$ acceleration voltage. The EBSD system was Channel 5 from HKL. For these ex situ analyses, specimens after 10 and $25 \%$ true compression at room temperature were selected. They were ground and vibration polished using 
colloidal silica and finally electropolished in order to avoid preparationinduced martensitic transformation. The scanned surface at $10 \%$ true compression amounted to $200 \times 115 \mu \mathrm{m}^{2}$, corresponding to approx. 1000 austenite grains. The step size of the measurements was $75 \mathrm{~nm}$. For the data analysis, a moderate clean-up was done, where unindexed pixels were replaced if at least 6 neighbouring pixels were assigned to the same phase and grain orientation. For the pole figure representations and orientation calculations, the MTEX toolbox $[82,83]$ was employed.

\section{Results and discussion}

\subsection{Texture evolution in $\gamma$-austenite}

The initial fine-grained austenitic steel exhibited a nearly random orientation distribution of crystallites, which was manifested by a uniform intensity distribution along the Debye-Scherrer rings in the 2D synchrotron XRD pattern. During uniaxial compression, a $\{110\}$ texture formed as expected for fcc materials [28-31,84]. The pole figures $\{111\}$, $\{100\}$ and $\{110\}$ of austenite obtained from the refined 2D diffraction data before compression and after $7 \%, 15 \%$ and $25 \%$ deformation are summarized in Figs. 1a-d. A gradual sharpening of the texture during the deformation process is visible from the increasing difference between the intensity maxima and minima in the respective pole figure. The plotted levels show the deviation from a random orientation distribution ( 1 on the intensity scale). Positions of the intensity maxima in the pole figures agree very well with the positions of the poles $\{111\},\{100\}$ and $\{110\}$ calculated for the fibre texture $\{110\}$, cf. Fig. 1 e.

\subsection{Texture evolution in $\varepsilon$-martensite}

During the sample compression, the metastable austenite transformed partly to hcp $\varepsilon$-martensite. First diffraction lines of $\varepsilon$-martensite were detected at $2 \%$ deformation, cf. section 3.4. In contrast to austenite, in which the texture degree increased steadily with increasing deformation, the crystallites of $\varepsilon$-martensite were strongly preferentially oriented already at a low load or, in other words, in the initial stage of the $\varepsilon$-martensite formation. The change in the degree of the preferred orientation of $\varepsilon$-martensite upon successive deformation seems to be smaller than for austenite. These experimental findings are illustrated by pronounced intensity maxima in all pole figures summarized in Fig. 2 and by a relatively small change of the maximum and minimum intensities in the respective pole figures despite increasing sample deformation.

The strong initial texture of $\varepsilon$-martensite suggests that the martensitic transformation $\gamma \rightarrow \varepsilon$ occurs preferentially in the austenite grains, which are favourably oriented with respect to the deformation direction. According to the Shoji \& Nishiyama OR from Eq. (1), the lattice plane $(110)_{\gamma}$ is almost parallel to the lattice plane $(\overline{1} 103)_{\varepsilon}$, cf. Fig. 3 . Thus, the observed fibre texture in $\varepsilon$-martensite, which is close to $\{10 \overline{1} 3\}$, is an expected consequence of the crystal lattice correspondence between austenite and $\varepsilon$-martensite. The anticipated appearance of the pole figures $\{0001\},\{11 \overline{2} 0\}$ and $\{10 \overline{1} 3\}$ of $\varepsilon$-martensite is depicted in Fig. $2 \mathrm{~d}$. The intensity maximum in the pole figure $\{10 \overline{1} 3\}$ (right column in Figs. 2a-c) is relatively broad, because the lattice planes $(110)_{\gamma}$ and $(\overline{1} 103)_{\varepsilon}$ are mutually inclined by $\sim 3^{\circ}$. The interrelationships between the texture evolution in these phases are discussed in detail in section 3.4 .

\subsection{Texture evolution in bcc $\alpha$-martensite}

The onset of the bcc $\alpha$-martensite formation was detected at $5 \%$ compression. The pole figures $\{110\},\{100\}$ and $\{111\}$ measured at $7 \%$, $15 \%$ and $25 \%$ deformation (Fig. 4 ) indicate the formation of a mixed $\{100\} \&\{111\}$ fibre texture, which is a typical feature of bcc metals under uniaxial compression $[28,85]$. The positions of the intensity maxima in the pole figures determined from the 2D XRD patterns (Figs. 4a-c) can be reproduced most successfully assuming a $\{111\}$ fibre texture oriented along the deformation direction (centre of the pole figure) and a $\{100\}$ fibre texture, which is slightly inclined $\left(\sim 5^{\circ}\right)$ from the deformation direction (cf. Fig. 4d). The symmetrical fibre texture $\{111\}_{\alpha^{\prime}}$ results from the coincidence of the poles $1 \overline{1} 1_{\alpha^{\prime}}, 1 \overline{1} 0_{\gamma}$ and $11 \overline{2} 0_{\varepsilon}$, the inclined fibre texture $\{100\}_{\alpha^{\prime}}$ from the proximity of the poles $010_{\alpha^{\prime}}$, $011_{\gamma}$ and $0 \overline{1} 13_{\varepsilon}$ (Fig. 3).

The inclined texture $\{100\}_{\alpha}$ results from the Kurdjumov-Sachs OR of $\alpha$-martensite to the $\{110\}$ preferred oriented austenite. In the Kurdjumov-Sachs OR from Eq. (3), the mutual tilt of the lattice planes $(010)_{\alpha^{\prime}}$ and $(011)_{\gamma}$ is about $5^{\circ}$ (see Fig. 3). This tilt leads to an inclination of the texture axis $\langle 100\rangle_{\alpha^{\prime}}$ from the deformation direction and, in the simulated pole figures (Fig. 4d), to a broadening of the originally distinct maxima of the pole densities to ring-shaped belts. In the pole figure $\{110\}_{\alpha^{\prime}}$, the expected maxima of the pole density $\{100\}_{\alpha^{\prime}}$ extend between the azimuth angles $(\Psi) 35^{\circ}$ and $55^{\circ}$ and beyond $80^{\circ}$, in the pole figure $\{100\}_{\alpha^{\prime}}$ between $0^{\circ}$ and $10^{\circ}$ and beyond $80^{\circ}$, and in the pole figure $\{111\}_{\alpha^{\prime}}$ between $48^{\circ}$ and $62^{\circ}$ (Fig. 4d). Texture $\{111\}_{\alpha^{\prime}}$ is also an intrinsic texture component of $\alpha$-martensite deformed in compression. The texture component $\{111\}_{\alpha}$ produces pole density rings having the average distances $35.3^{\circ}$ and $90^{\circ}$ from the centre of the pole figure $\{110\}_{\alpha^{\prime}}, 54.7^{\circ}$ in the pole figure $\{100\}_{\alpha^{\prime}}$, and $0^{\circ}$ and $70.5^{\circ}$ in the pole figure $\{111\}_{\alpha^{\prime}}$. Some of the intensity rings of the texture component $\{111\}_{\alpha}$, are located within the belts of the expected pole density maxima of the $\{100\}_{\alpha^{\prime}}$ texture component. Like $\varepsilon$-martensite, also $\alpha$-martensite exhibits a strong texture already in the early stages of the deformation process. At the beginning of the $\alpha$-martensite formation, the dominant texture component is $\{100\}$ (Fig. $4 a$ ), while the $\{111\}$ component develops additionally at higher deformations (Fig. 4c). Still, both texture components become weaker with increasing deformation. The reasons for this behaviour are discussed in the following sections.

\subsection{Effect of the phase fractions on the preferred orientation of crystallites in individual phases}

As discussed above, the preferred orientation of crystallites in austenite is intensified at higher compressive deformations (Fig. 1). In contrast, the strongest textures in $\varepsilon$ - and $\alpha$-martensites were observed in the early stages of the respective phase formation, and declined apparently with increasing plastic deformation of the TRIP steel (Figs. 2 and 4). Quantitative correlations between the phase fractions and the texture degrees in individual phases that were obtained from the Rietveld refinement of the $2 \mathrm{D}$ diffraction patterns are shown in Fig. 5. As the phase fractions were refined together with the texture coefficients of the $E$-WIMV model in the MAUD routine, the phase compositions are not biased by the preferred orientation of crystallites in individual phases [86]. The texture degree is depicted in terms of the maximum intensity of selected poles (Fig. 5b) and in terms of the overall texture index (Fig. 5c), which is based on the refined coefficients $\left(C_{l}^{\mu}\right.$, where the indices $l$ and $\mu$ stand for the order and the index of the symmetric functions) of the orientation distribution function [28]:

$J=\frac{1}{4 \pi} \sum_{l, \mu}\left[C_{l}^{\mu}\right]^{2}$

The analysis of the in situ XRD patterns revealed that the martensitic transformation of the originally austenitic sample starts at $2 \%$ compression (Fig. 5a). Although the crystallites of austenite are still almost randomly oriented at this deformation, the crystallites of $\varepsilon$-martensite, which is the first martensitic phase appearing upon load, are strongly textured. With increasing deformation, the maximum intensity of the pole $110_{\gamma}$ (Fig. 5b) and the texture index of austenite (Fig. 5c) increase continuously. In contrast, the maximum intensity of the poles $\{10 \overline{1} 3\}_{\varepsilon}$ and $\{0001\}_{\varepsilon}$ and the texture index of $\varepsilon$-martensite remain constant up to the deformation of about $10 \%$, at which 

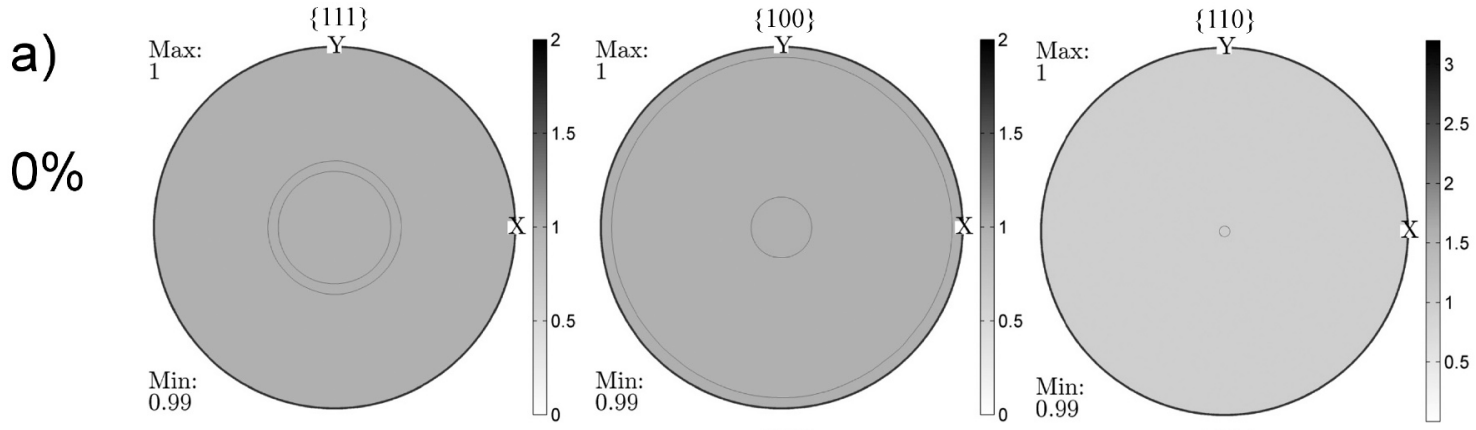

b)
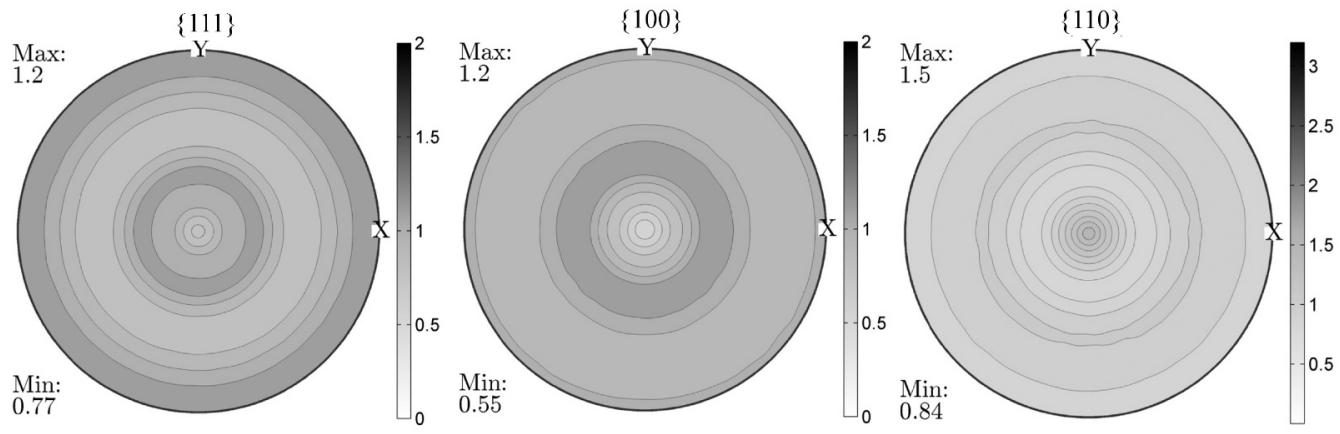

c)

$15 \%$
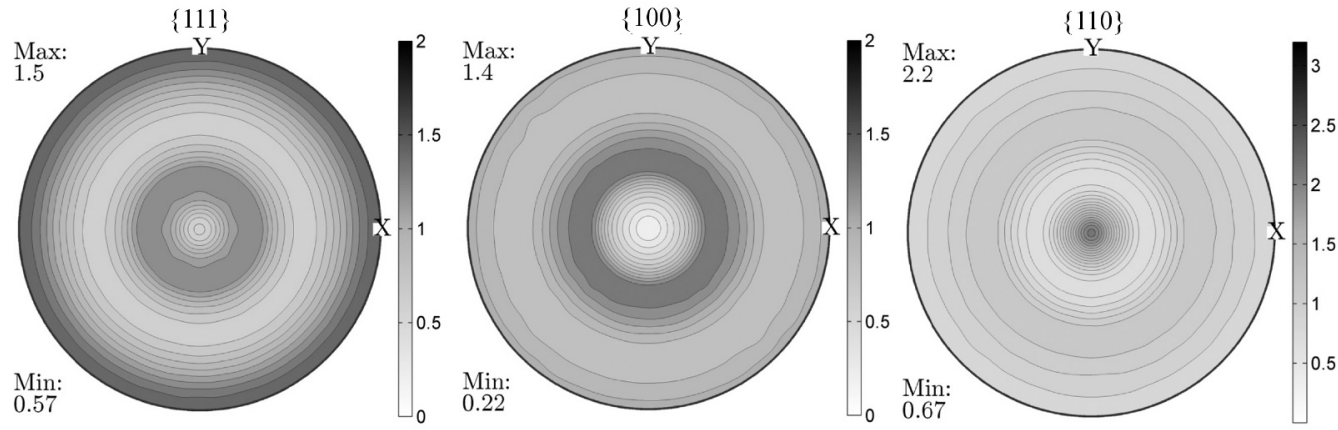

d)
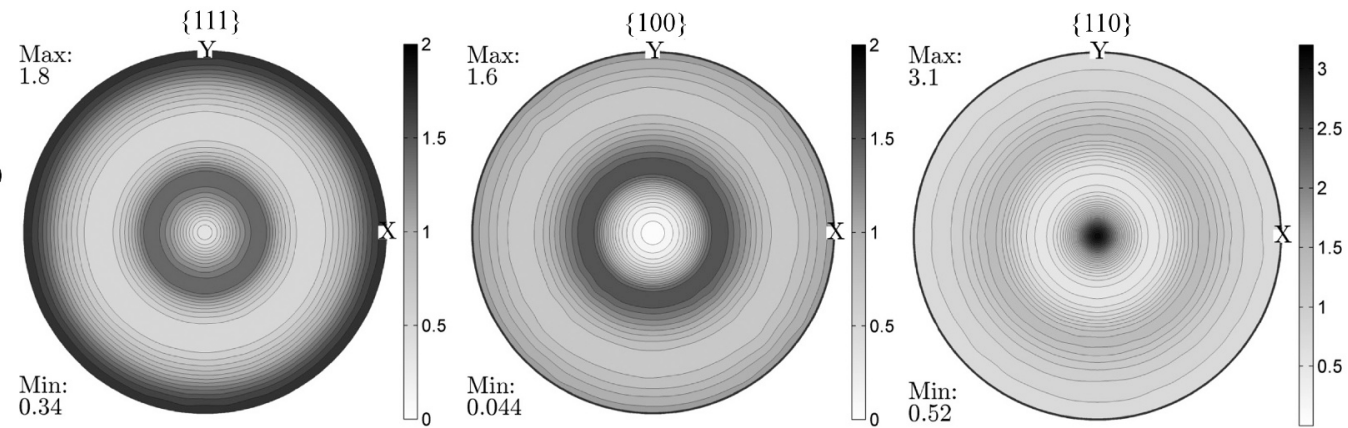

e)
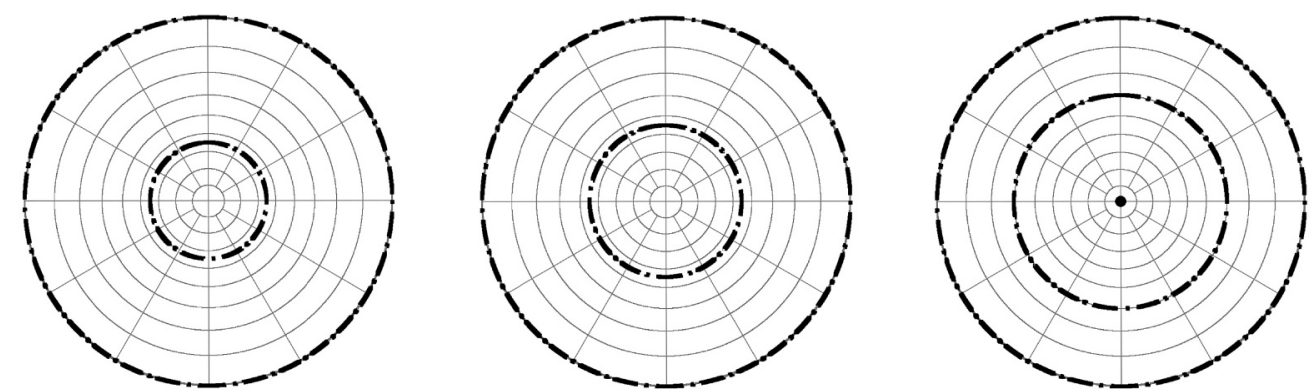

Fig. 1. Pole figures $\{111\},\{100\}$ and $\{110\}$ of fcc austenite obtained from the refinement of the 2D diffraction patterns using the E-WIMV texture model [75]. (a) Undeformed state, (b), (c) and (d) after 7\%, 15\% and 25\% compression, respectively. The deformation direction is located in the middle of the pole figures. The isolines correspond to $0.1 \mathrm{mrd}$ (multiples of the random distribution) steps. The numerical values (max. and min.) quantify the texture degree in terms of the deviation from a random orientation distribution (unity). (e) Positions of the intensity maxima in the pole figures $\{111\},\{100\}$ and $\{110\}$ expected for the fibre texture $\{110\}$. 
a)
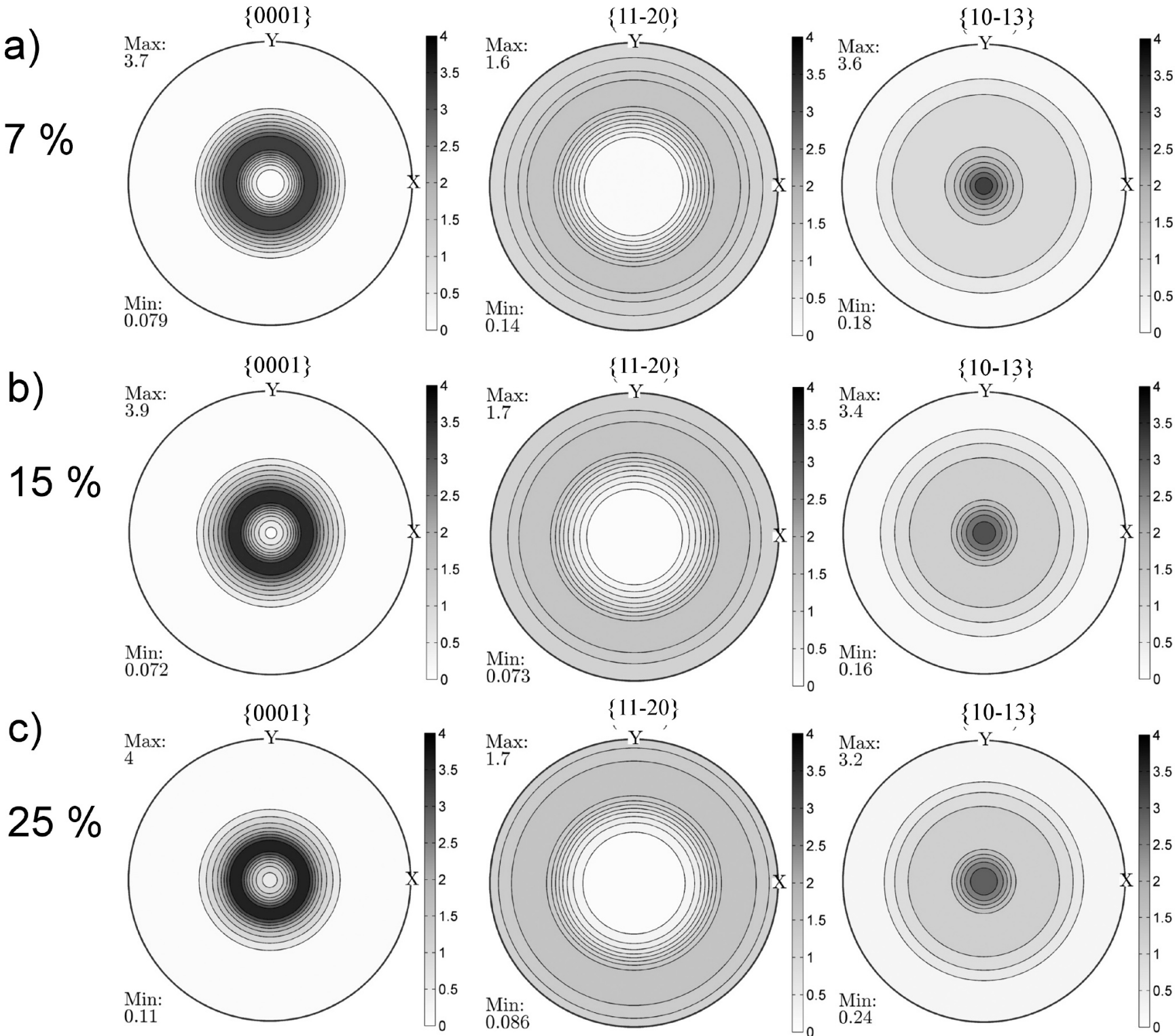

$\{11-20\}$

$\{10-13\}$
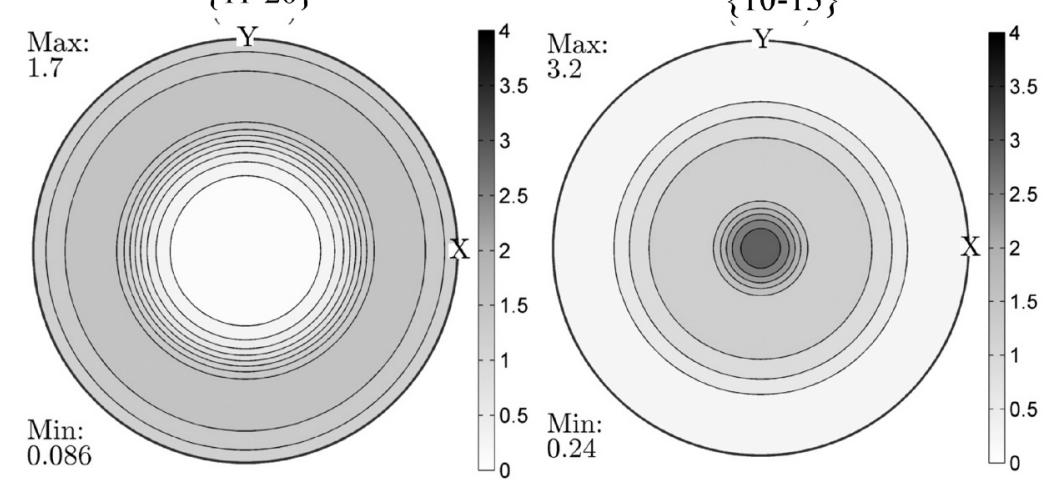

d)
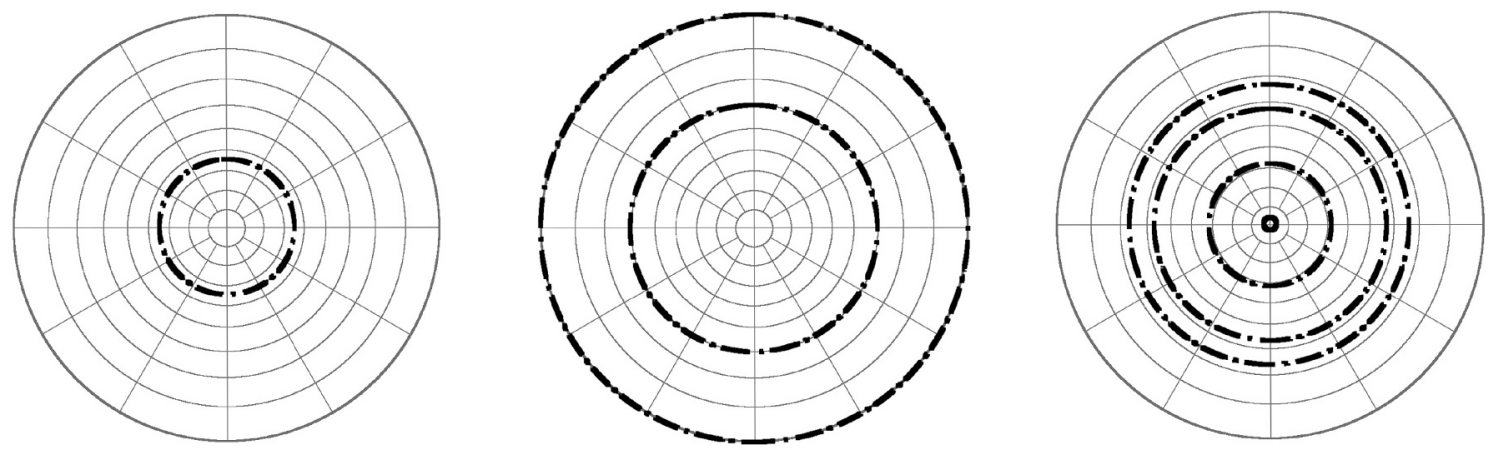

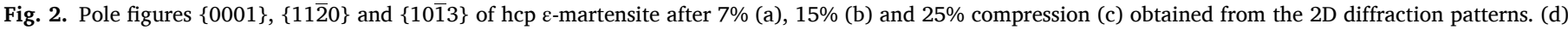
Positions of the highest pole densities calculated for $\varepsilon$-martensite having a $\{10 \overline{1} 3\}$ texture inclined about $3^{\circ}$ from the deformation direction.

$\alpha$-martensite starts to form faster and at the expense of $\varepsilon$-martensite. At the deformations exceeding $10 \%$, the density of the pole $\{10 \overline{1} 3\}_{\varepsilon}$ and the texture index of $\varepsilon$-martensite decrease slightly. At small deformations between $5 \%$ and $7.5 \%$, $\alpha$-martensite is a minor phase. The first crystallites of $\alpha$-martensite follow the texture of $\varepsilon$-martensite. They are oriented preferentially with their $\{100\}_{\alpha^{\prime}}$ directions parallel to the load direction. With increasing amount of $\alpha$-martensite in the sample, i. e., at the deformations beyond $7.5 \%$, the pole density $\{100\}_{\alpha^{\prime}}$ and the texture index of $\alpha$-martensite decrease rapidly. The decay of the texture component $\{111\}_{\alpha^{\prime}}$ is much less pronounced. 


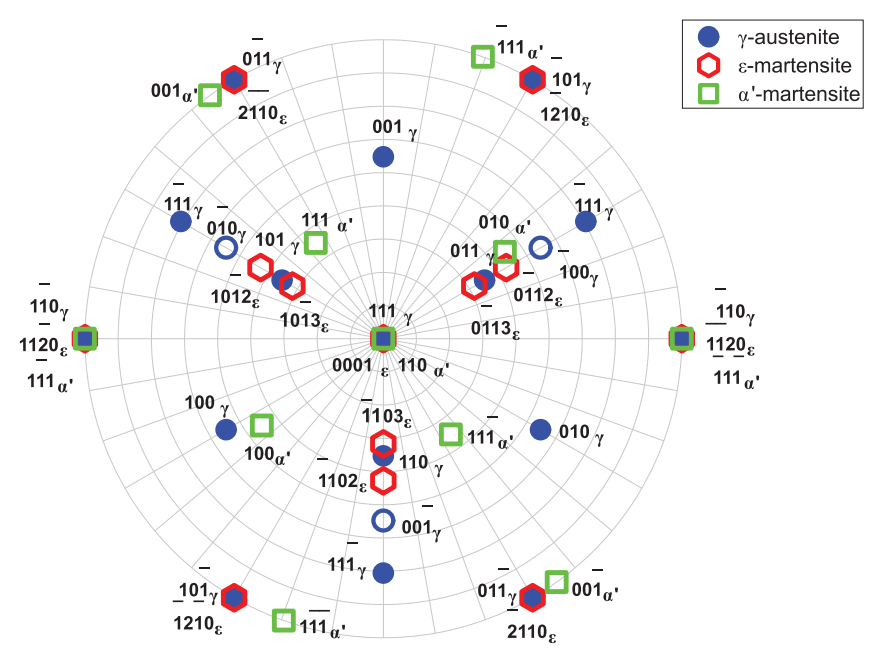

Fig. 3. Simplified stereographic projection showing the correspondence of the reciprocal space directions in fcc $\gamma$-austenite, hcp $\varepsilon$-martensite and bcc $\alpha$-martensite for the orientation relationships $\{111\}_{\gamma}\left\|\{0001\}_{\varepsilon}\right\|\{110\}_{\alpha^{\prime}}$ and $\langle 1 \overline{1} 0\rangle_{\gamma}\left\|\langle 11 \overline{2} 0\rangle_{\varepsilon}\right\|\langle 1 \overline{1} 1\rangle_{\alpha^{\prime}}$ from Eqs. (1) to (3).

The presence of a strong $\{10 \overline{1} 3\}$ texture in $\varepsilon$-martensite is a consequence of the $\gamma \rightarrow \varepsilon$ transformation, which takes place via formation of stacking faults on every second lattice plane $\{111\}$ of austenite $[9,17]$ and which leads to the Shoji-Nishiyama orientation relationship [Eq. (1)]. The formation and the widening of stacking faults in austenite are promoted, when the external compressive force acts in a $\langle 100\rangle_{\gamma}$ direction $[33,87]$. Therefore, $\varepsilon$-martensite is formed first in the austenite grains having a $\{100\}$ orientation with respect to the compression direction $[33,39]$. Because of the proximity of the lattice planes $(\overline{1} 00)_{\gamma},(0 \overline{1} 1 \overline{2})_{\varepsilon}$ and $(0 \overline{1} 1 \overline{3})_{\varepsilon}$ as well as the crystallographically equivalent ones (s. Fig. 3), the preferential martensitic transformation of the $\{100\}$ oriented crystallites of austenite leads to a strong preferred orientation of the crystallites of $\varepsilon$-martensite that is close to $\{10 \overline{1} 3\}$ already in the initial stage of the $\varepsilon$-martensite formation. However, the formation of the deformation texture $\{110\}_{\gamma}$ in austenite impedes the further martensitic transformation $\gamma \rightarrow \varepsilon$, because the austenite crystallites rotate out of the $\{100\}_{\gamma}$ direction, which is favourable for the formation and widening of the stacking faults on the $\{111\}_{\gamma}$ planes. Still, as the reciprocal space directions $\{10 \overline{1} 3\}_{\varepsilon}$ are close to the reciprocal space directions $\{110\}_{\gamma}$ in the Shoji-Nishiyama orientation relationship (Fig. 3), the texture degree in $\varepsilon$-martensite does not change much during the deformation process (Fig. 5 b, c).

The preferred orientation in $\alpha$-martensite is affected by the transformation texture of $\varepsilon$-martensite and by the Burgers orientation relationship between $\alpha$ - and $\varepsilon$-martensite (cf. Eq. (2)). The proximity of the poles $010_{\alpha^{\prime}}, 0 \overline{1} 12_{\varepsilon}, 0 \overline{1} 13_{\varepsilon}$ and $011_{\gamma}$ (Fig. 3) favours the $\{100\}_{\alpha}$ texture at the beginning of the $\alpha$-martensite formation (Fig. 5b). With increasing deformation and with increasing amount of $\alpha$-martensite, the pole density $\{100\}_{\alpha^{\prime}}$ and the texture index of $\alpha$-martensite decrease rapidly. The anticipated reasons for this behaviour are the variant selection and the incompatibility of some symmetry operations in $\alpha$-martensite with the symmetry operations in $\gamma$-austenite and $\varepsilon$-martensite, when these phases obey the Shoji-Nishiyama, Burgers and Kurdjumov-Sachs orientation relationships (Fig. 3). At a higher amount of $\alpha$-martensite in the plastically deformed sample, the formation of new $\alpha$-martensite nuclei with the initial orientation is inhibited, because they would produce large strain in the surrounding matrix [55], which is typically a deformation band containing $\varepsilon$-martensite having a slightly smaller molar volume than the $\alpha$-martensite [9]. Instead, the new $\alpha$-martensite crystallites nucleate and grow with different orientations, which reduce the deformation energy in the new local stress situation [88]. However, as these $\alpha$-martensite variants usually do not follow the original transformation texture, the texture degree in $\alpha$-martensite can decline with increasing deformation as observed experimentally (Fig. 5). Instead, the intrinsic bcc deformation texture $\{111\}$ gains in importance, in particular in further deformation stages.

\subsection{The variant selection}

The variant selection during the martensitic transformation that was derived from the texture development observed in the in situ synchrotron radiation diffraction experiment was verified by the orientation analysis of individual phases using EBSD. For this purpose, a sample compressed to $10 \%$ was selected, as it represents early transformation stages, for which the transformation texture is most pronounced (cf. Figs. 2, 4 and 5). The results of the EBSD analysis are substantiated by the amount of a 'transformation work' that was calculated as the deformation energy resulting from the martensitic transformations $\gamma \rightarrow \varepsilon$ and $\varepsilon \rightarrow \alpha^{\prime}$ under external stress. In general, the deformation energy is given by the double dot product of the strain tensor $\left(\varepsilon_{i j}\right)$ with the stress tensor $\left(\sigma_{i j}\right)[89]$ :

$W=\frac{1}{2} \sigma_{i j} \cdot \varepsilon_{i j}$

The deformation tensor describes the lattice deformation caused by the martensitic phase transformation for the respective orientation variant. For the phase transformation $\gamma \rightarrow \varepsilon$ following the Shoji \& Nishiyama orientation relationship, the strain tensor can be expressed as $[56,90]$.

$\varepsilon^{\gamma \rightarrow \varepsilon}=\frac{1}{24}\left[\begin{array}{ccc}2 & 2 & -1 \\ 2 & 2 & -1 \\ -1 & -1 & -4\end{array}\right]$

For the $\varepsilon \rightarrow \alpha^{\prime}$ transformation following the Burgers orientation relationship, the strain tensor is given by $[56,90]$.

$\varepsilon^{\varepsilon \rightarrow \alpha^{\prime}}=\left[\begin{array}{ccc}\frac{\sqrt{3} a_{\alpha^{\prime}}}{2 a_{\varepsilon}}-1 & -\frac{a_{\alpha^{\prime}}}{12 a_{\varepsilon}} & 0 \\ -\frac{a_{\alpha^{\prime}}}{12 a_{\varepsilon}} & \frac{\sqrt{8} a_{\alpha^{\prime}}}{3 a_{\varepsilon}}-1 & 0 \\ 0 & 0 & \frac{\sqrt{2} a_{\alpha^{\prime}}}{c_{\varepsilon}}-1\end{array}\right]$,

where $a_{\varepsilon}, c_{\varepsilon}$ and $a_{\alpha^{\prime}}$ are the lattice parameters of the $\varepsilon$ - and $\alpha$-martensites. For the calculation of the lattice strain, the values $a_{\varepsilon}=2.540 \AA, c_{\varepsilon}=$ $4.111 \AA$ and $a_{\alpha^{\prime}}=2.875 \AA$ from [9] were used. Both transformation strain tensors, $\varepsilon^{\gamma \rightarrow \varepsilon}$ and $\varepsilon^{\varepsilon \rightarrow \alpha^{\prime}}$, are oriented with respect to a reference frame of the respective parent phases. For the calculation of the transformation work according to Eq. (5), however, the strain tensor and the stress tensor must refer to the same coordinate system. Therefore, the strain tensors were rotated to comply with the orientation of the respective grain with respect to the applied load. In the case of the uniaxial load, the calculation of the transformation work is reduced to the product of the single component of the stress tensor describing the uniaxial load with the corresponding component of the appropriately rotated strain tensor $\varepsilon^{\gamma \rightarrow \varepsilon}(g)$ or $\varepsilon^{\varepsilon \rightarrow \alpha^{\prime}}(g)$. The rotation of the respective strain tensor and its dependence on the local grain orientation are expressed by the explicit dependence of $\varepsilon^{\gamma \rightarrow \varepsilon}(g)$ or $\varepsilon^{\varepsilon \rightarrow \alpha^{\prime}}(g)$ on the orientation matrix $g$. For compressive load, the variants with the highest negative value of the transformation work are considered as most favourable, because they can accommodate the compressive deformation best.

In the example shown in Fig. $6 \mathrm{a}$, the $\varepsilon$ - and $\alpha$-martensites form in a 
a)

$7 \%$
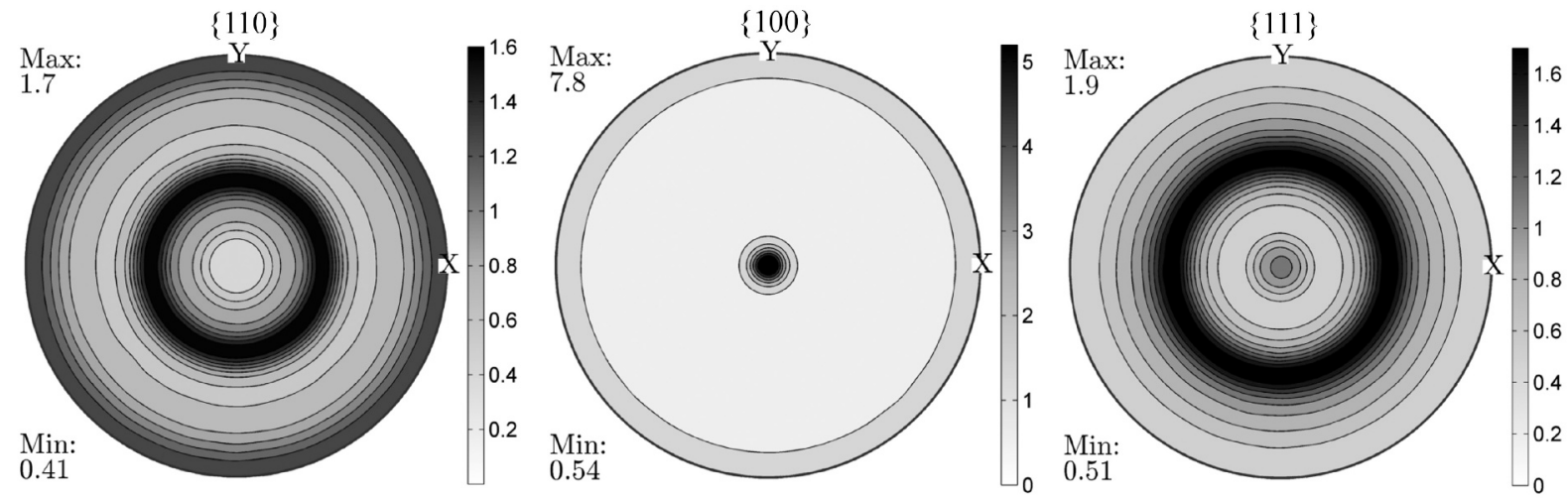

b)

$\underset{1.4}{\operatorname{Max}}$

$\{110\}$

$15 \%$
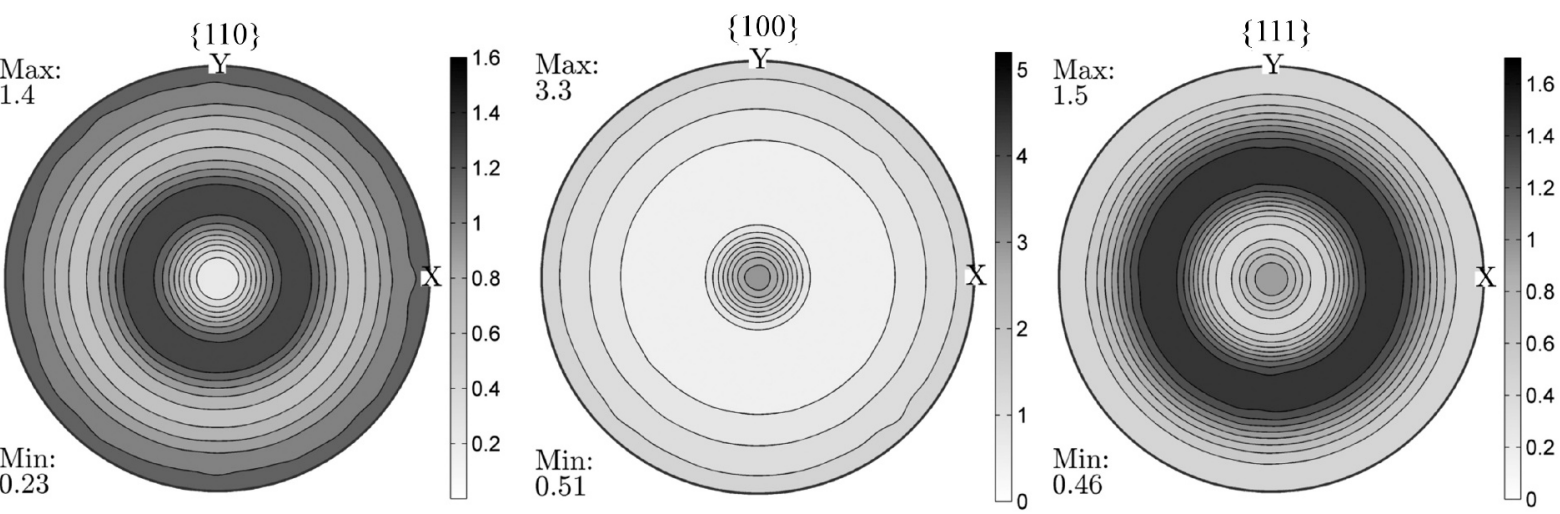

c)
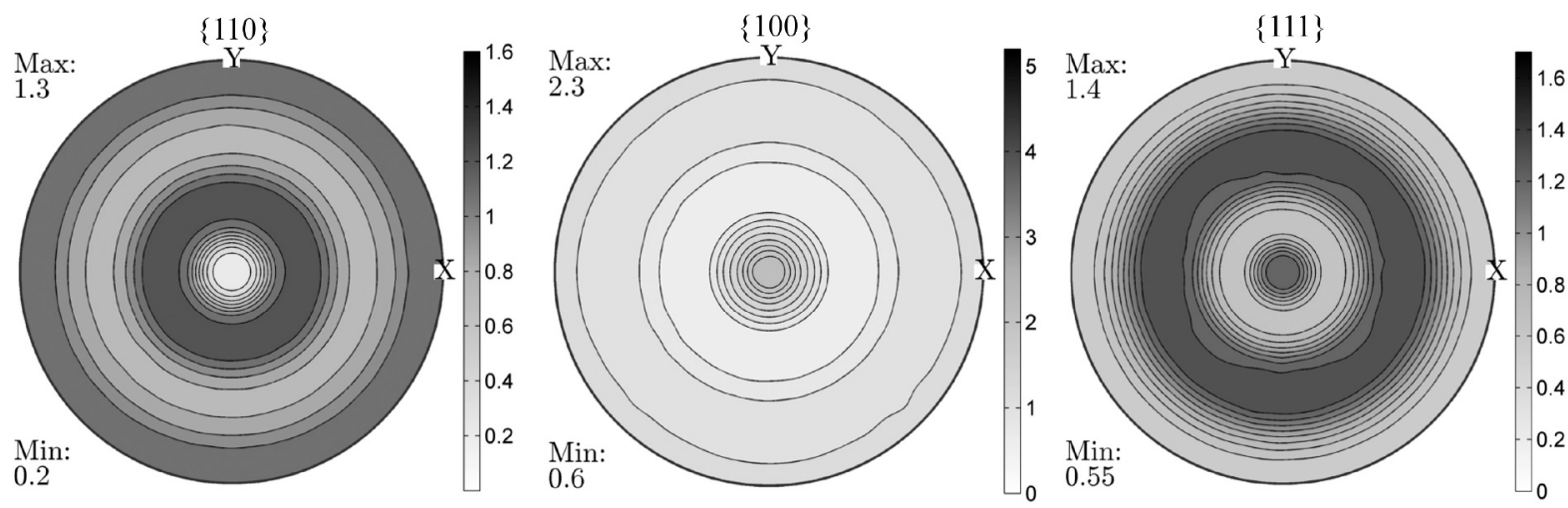

d)
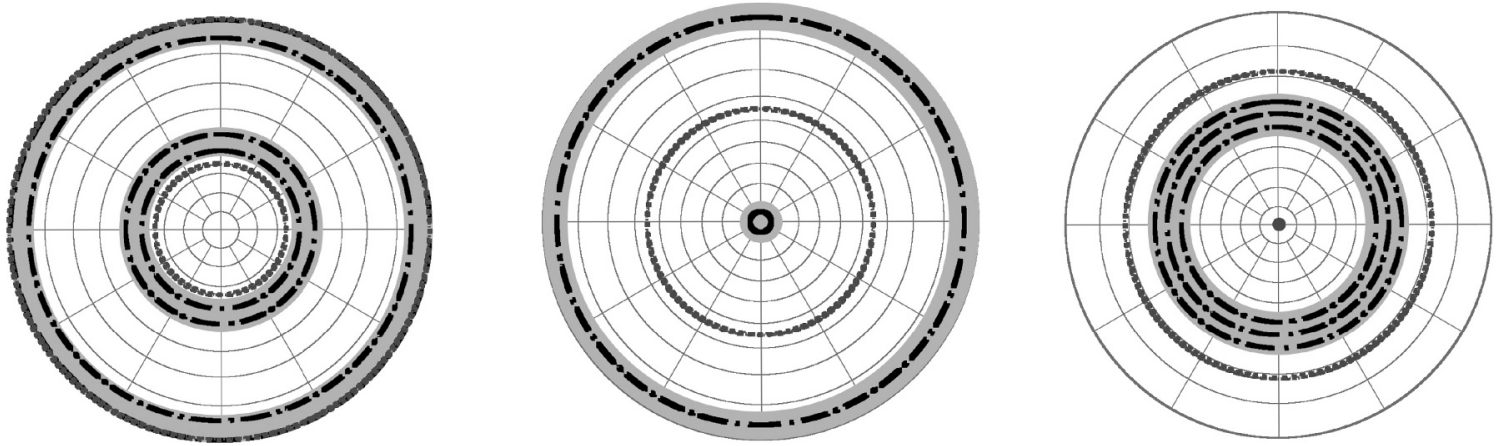

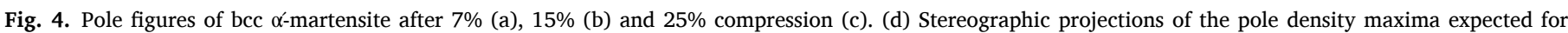

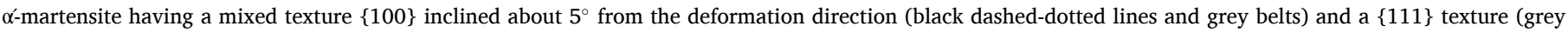
dotted lines).

deformation band, which is a part of an original austenite grain having the orientation marked by the large filled circle in Fig. 6d. The Euler angles of this grain are $\phi_{1}=98^{\circ}, \Phi=43.6^{\circ}$ and $\phi_{2}=10.2^{\circ}$. The orientations of the martensite regions are depicted in the inverse pole figures (Fig. 6e and f) by filled symbols. The normal direction to this deformation band, which is located on the lattice plane $\{1 \overline{1} 1\}_{\gamma}$ (white dashed line in Fig. $6 \mathrm{a}$ ), is inclined about $45^{\circ}$ from the direction of the applied load. This orientation of the austenite grain is advantageous for the dissociation of the perfect dislocations $\frac{a}{2}[110](1 \overline{1} 1)$ and for widening of the stacking faults, as it can be seen on a high value of the Schmid 

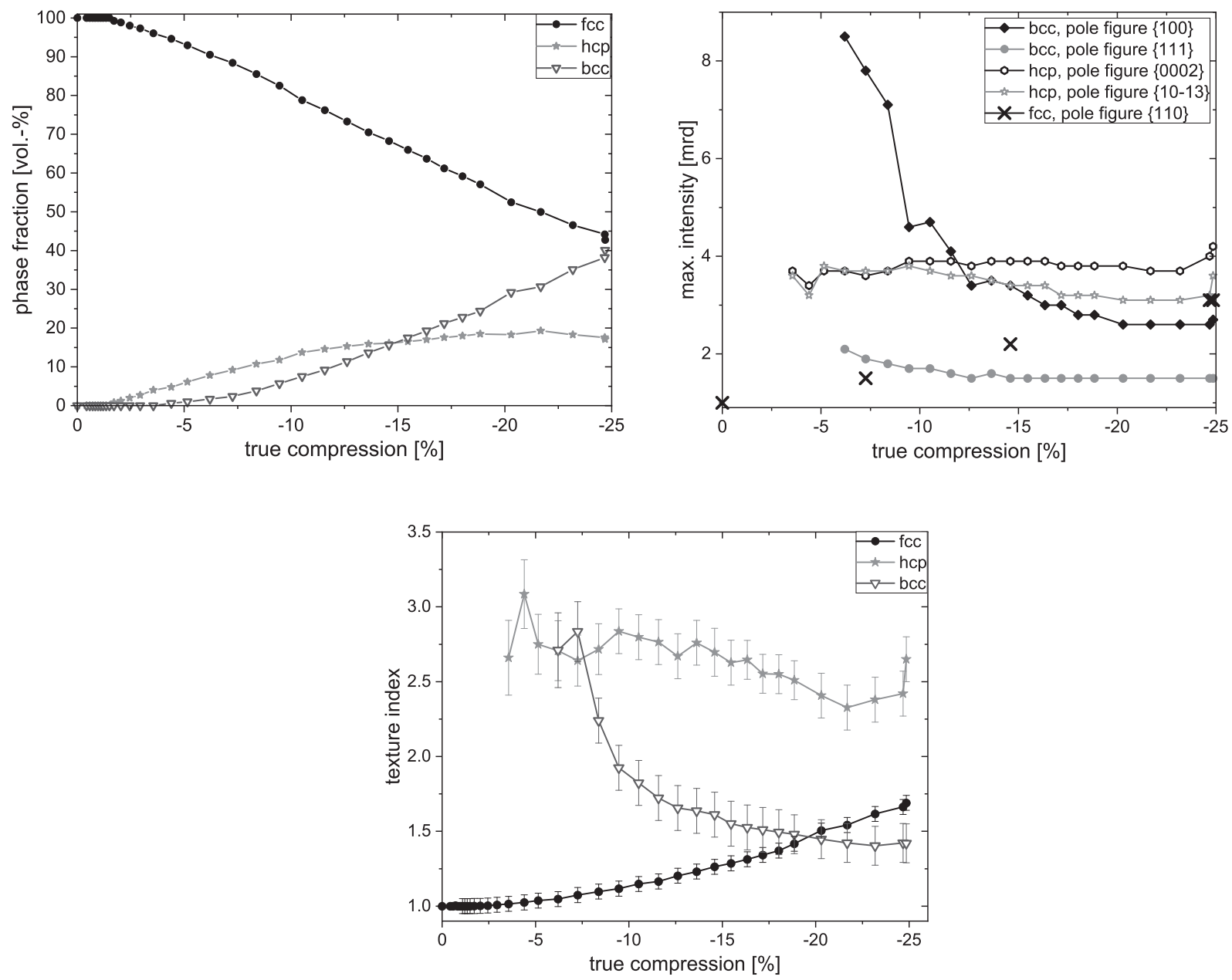

Fig. 5. Evolutions of the phase fractions (a), of the maximum intensity of the characteristic poles of individual phases (b) and the texture indices [Eq.(4)] (c) during the in situ compression test.

factor (0.483) of the leading partial dislocation $\frac{a}{6}[121](1 \overline{1} 1)$ that was calculated using MTEX [82,83]. The maximum Schmid factors of perfect dislocations $\frac{a}{2}\langle 110\rangle\{111\}$ and of leading partial dislocations $\frac{a}{6}\langle 1 \overline{2} 1\rangle$ $\{111\}$ calculated for other, crystallographically equivalent slip systems are summarized in Table 1 . The two other austenite orientations visible in the orientation map (blue and green areas in Fig. 6a) do not exhibit pronounced stacking fault formation, as they are unfavourably oriented for the partial dislocation dissociation [33,36,39].

A high probability of the martensitic phase transformation $\gamma \rightarrow \varepsilon$ on the austenitic lattice plane $(1 \overline{1} 1)$ in Fig. $6 \mathrm{a}$ is supported additionally by a highly negative transformation strain, which is -0.171 for this particular transformation variant (see Table 1). In Table 1, the values of the transformation strain are expressed in terms of $\varepsilon_{z z}^{\gamma \rightarrow \varepsilon}$, i.e., as single components of the deformation matrix $\varepsilon^{\gamma \rightarrow \varepsilon}$ from Eq. (6), which was rotated into the direction of the applied load. The transformation strain calculated for the crystallographically equivalent lattice planes $(\overline{1} 11)_{\gamma}$, $(111)_{\gamma}$ and $(11 \overline{1})_{\gamma}$ of austenite is less negative than the transformation strain calculated for $(1 \overline{1} 1)_{\gamma}$, which means that the observed variant of $\varepsilon$-martensite (Fig. 6 b) is most favoured also from the point of view of the transformation work.

The example of the preferred $\varepsilon$-martensite variant from Fig. 6 and the results of the EBSD experiments carried out on other partially transformed austenite grains support the above claim that the martensitic transformation $\gamma \rightarrow \varepsilon$ occurs preferentially for the variants, which are associated with the maximum negative deformation energy. Concurrently, this example illustrates the importance of the Schmid factor, which must be sufficiently high for the leading partial dislocation in order to facilitate the widening of the stacking faults in austenite. The examination of 50 austenite grains confirmed that in more than $90 \%$ of the cases, the $\varepsilon$-martensite variant with the minimum transformation strain in the load direction was formed. Additionally, the maximum Schmid factor criterion for partial dislocations was satisfied in all cases. This makes the orientation dependence of the Schmid factor quite important for the variant selection [53,54,65,91]. Fig. 7 compares the orientation dependence of the deformation energy obtained from $\varepsilon_{z z}^{\gamma \rightarrow \varepsilon}$ (panel a) with the orientation dependence of the Schmid factor of the leading partial dislocation (panel b). Both orientation dependencies are related to the orientation of the original austenite grain with respect to the deformation direction. From this comparison, it follows that the effect of the Schmid factor and the effect of the deformation energy are congruent. As the phase transformation $\gamma \rightarrow \varepsilon$ happens via formation of stacking faults in austenite, the strain tensor $\varepsilon^{\gamma \rightarrow \varepsilon}$ is related to the direction of the Burgers vector of the partial dislocations. Consequently, the Schmid factor of the leading partial dislocation and the deformation energy depend equally on the orientation of the transforming grain under external load as illustrated in Fig. 7. The comparison of Fig. 7 with Fig. $6 \mathrm{~d}$ confirms once more that the orientation of the preferentially transformed austenitic grain from Fig. 6a is located within the range of the beneficial orientations indicated by a highly negative transformation work and high Schmid factor of the leading partial dislocations responsible for the propagation of the stacking faults. 

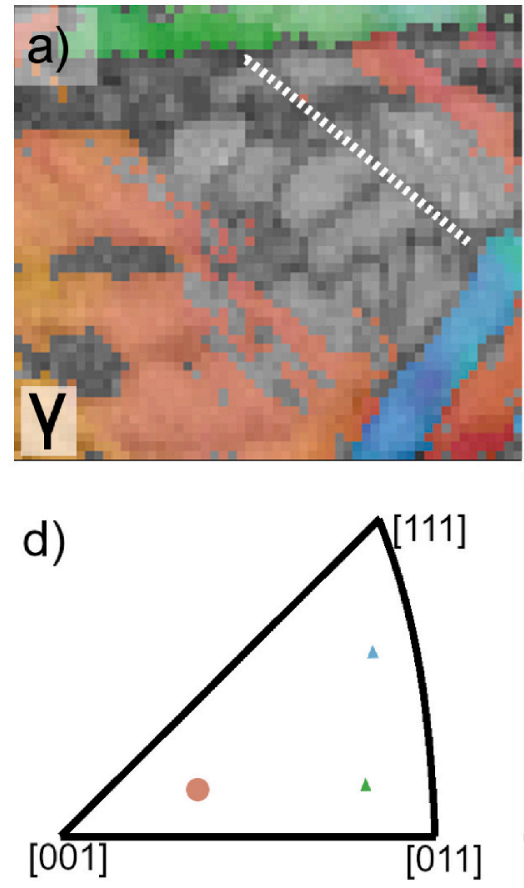

g)

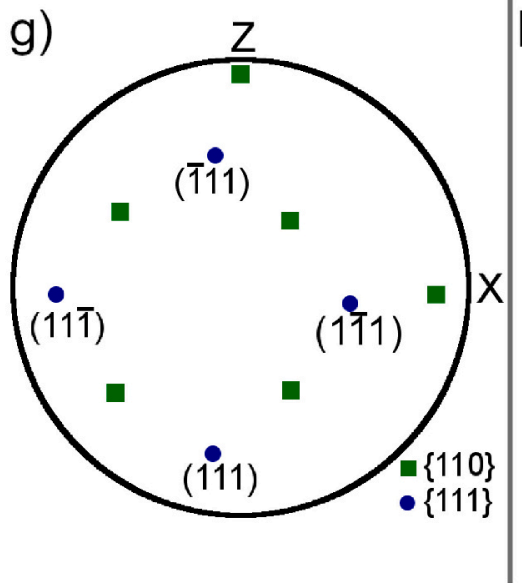

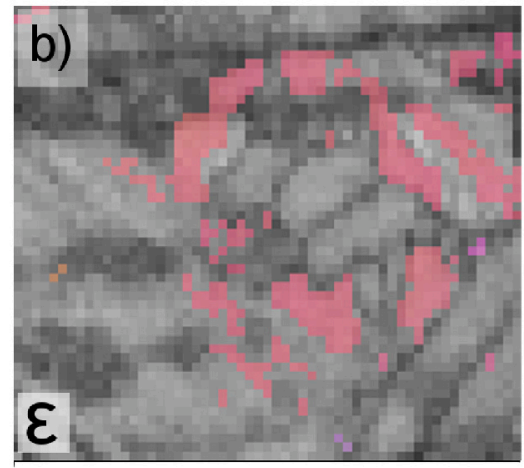
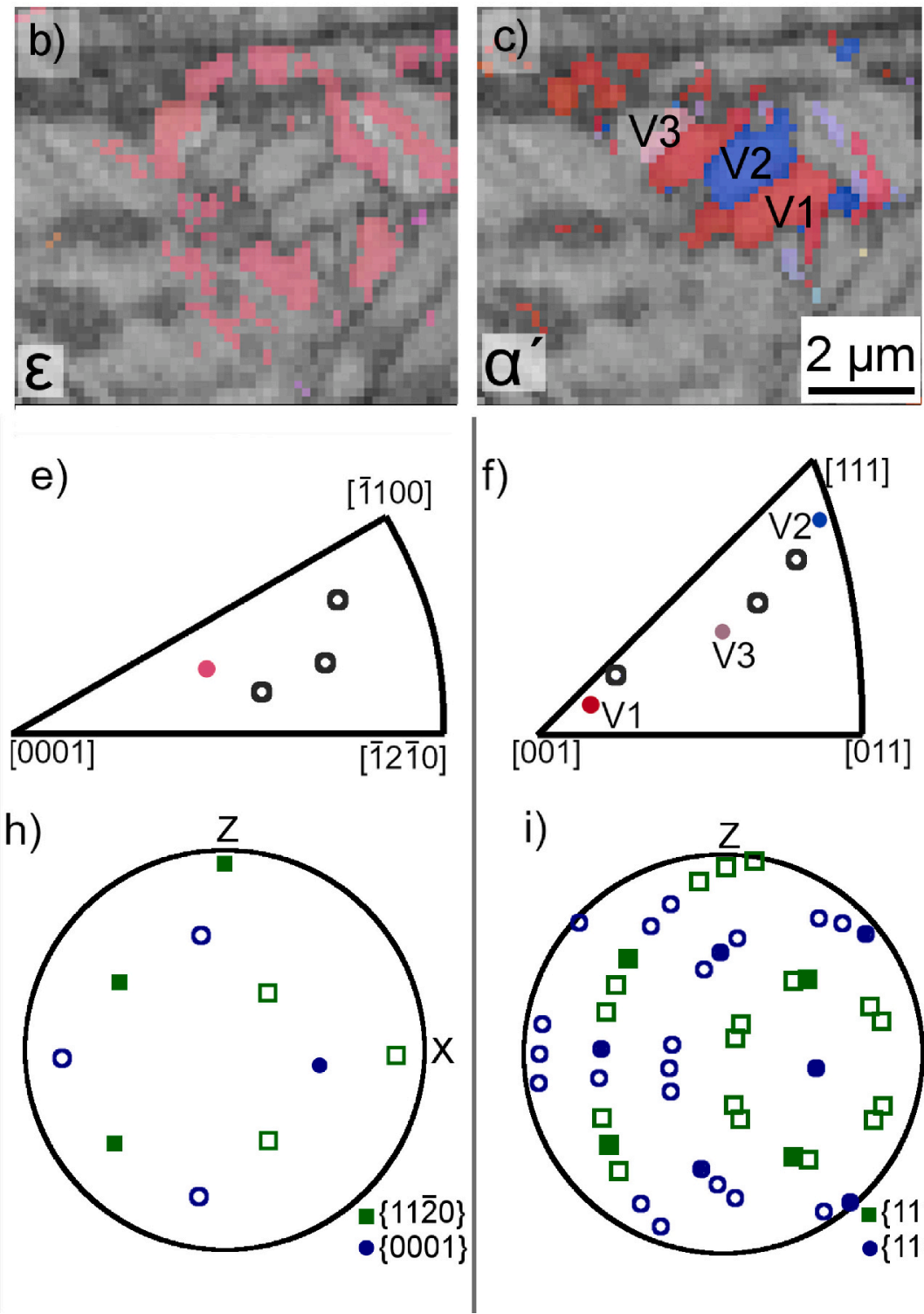

i)

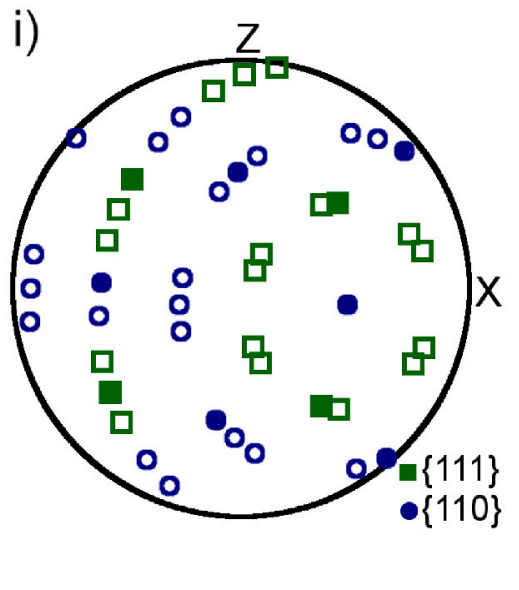

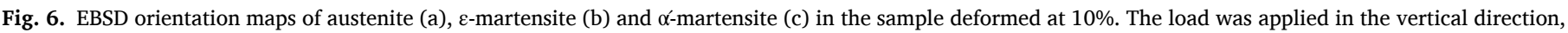

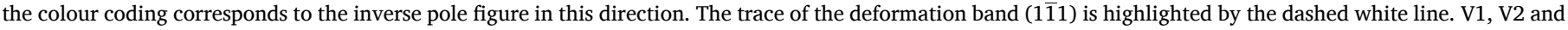

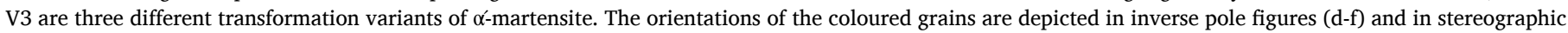

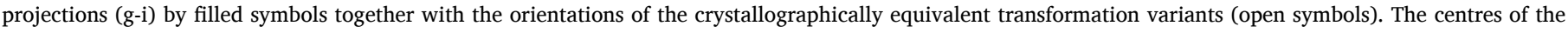
stereographic projections correspond to the load direction, their $\mathrm{x}$ axes to the horizontal directions in panels (a-c).

Table 1

The Schmid factors of the perfect dislocations $\frac{\mathrm{a}}{2}\langle 1 \overline{1} 0\rangle\{111\}$ and the leading partial dislocations $\frac{\mathrm{a}}{6}\langle 1 \overline{2} 1\rangle\{111\}$ in austenite, and the values of the transformation strain $\varepsilon_{\mathrm{ZZ}}^{\gamma \rightarrow \varepsilon}$ for all transformation variants, which results from the crystallographic equivalence of the $\{111\}_{\gamma}$ planes. The values of the experimentally observed variant are highlighted.

\begin{tabular}{lllll}
\hline Slip plane & $(1 \overline{1} 1)$ & $(\overline{1} 11)$ & $(111)$ & $(11 \overline{1})$ \\
\hline $\begin{array}{l}\text { max. Schmid factor (perfect } \\
\text { dislocations) }\end{array}$ & 0.466 & 0.488 & 0.391 & 0.295 \\
$\begin{array}{c}\text { max. Schmid factor (partial } \\
\text { dislocations) }\end{array}$ & $\mathbf{0 . 4 8 3}$ & 0.464 & 0.384 & 0.316 \\
$\varepsilon_{z z}^{\gamma \rightarrow \varepsilon}$ & $-\mathbf{0 . 1 7 1}$ & -0.164 & -0.136 & -0.112 \\
\hline
\end{tabular}

Analogous calculations of the transformation work were performed for all six variants of the $\varepsilon \rightarrow \alpha^{\prime}$ transformation (Fig. $6 \mathrm{f}$ and i), which follow the Burgers orientation relationship from Eq. (2). The results of these calculations are summarized in Table 2. Also in this case, the martensitic variant with the highest negative transformation work dominates (V1 in Fig. 6c). The other variants (V2 and V3) balance the

\section{Table 2}

The transformation strains calculated for all possible variants of $\alpha$-martensite, which can be formed from the $\varepsilon$-martensite having the observed orientation (Fig. 6b). The variants V1, V2 and V3 of $\alpha$-martensite were detected by EBSD (Fig. 6c).

\begin{tabular}{|c|c|c|c|c|c|c|}
\hline Variant & V1 & V3 & & & & V2 \\
\hline$\varepsilon_{z z}^{\varepsilon \rightarrow \alpha^{\prime}}$ & -0.072 & -0.052 & -0.035 & -0.024 & 0.376 & 5.09 \\
\hline $\begin{array}{l}\text { Euler } \\
\text { angles } \\
{\left[^{\circ}\right]}\end{array}$ & $\begin{array}{l}322.1 / \\
5.2 / 45.5\end{array}$ & $\begin{array}{l}236.2 / \\
50 / 36.5\end{array}$ & & & & $\begin{array}{l}162.5 / \\
42.9 / 60.5\end{array}$ \\
\hline
\end{tabular}



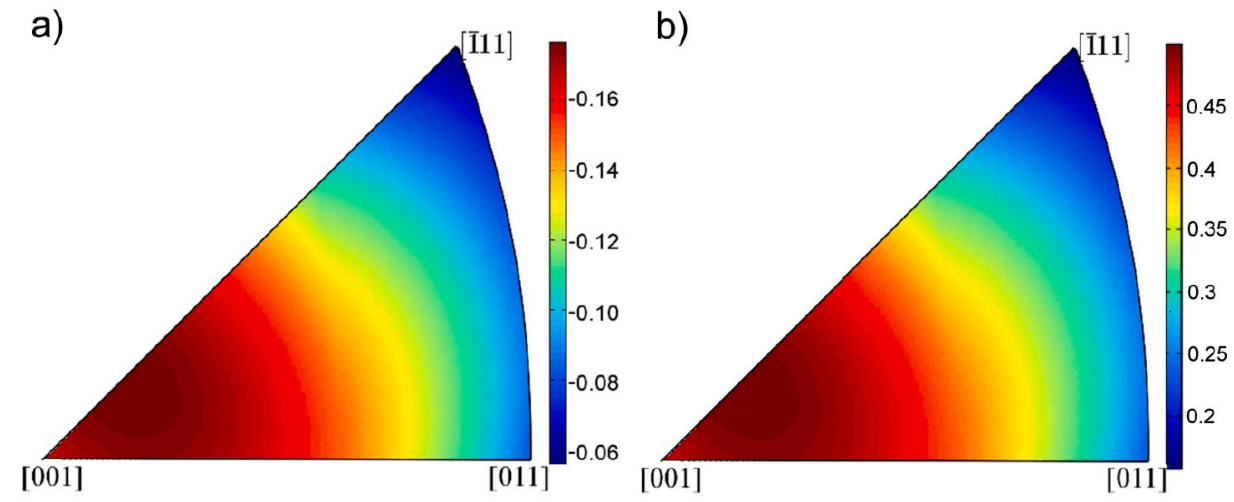

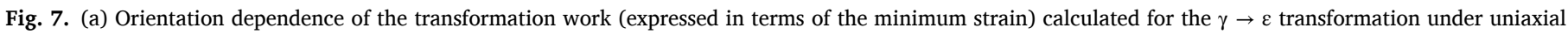

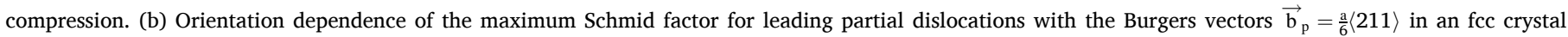
structure under compressive load. The Schmid factors were calculated using the MTEX routine [82,83].

volume expansion and the resulting shear $[55,65,91]$. V2 is twin-related to V1. Like for the first transformation step $\gamma \rightarrow \varepsilon$, also the results of the $\varepsilon$ $\rightarrow \alpha^{\prime}$ transformation were verified by the EBSD analysis of further deformation bands containing $\alpha$-martensite.

\subsection{Interplay between the transformation texture and the variant selection}

Although the probability of the martensitic transformation according to a specific variant is generally controlled by the transformation work, there are obvious differences in the texture development during the $\gamma \rightarrow$ $\varepsilon$ and $\varepsilon \rightarrow \alpha^{\prime}$ transformations (Fig. 5). The $\gamma \rightarrow \varepsilon$ transformation following the Shoji \& Nishiyama orientation relationship can occur in four variants, which are associated with differently oriented lattice planes $\{111\}_{\gamma}$ of austenite (Fig. 6). Still, due to the matching symmetry operations $\overline{3}$ and $6_{3} / m$ in austenite and in $\varepsilon$-martensite, there are no additional orientation variants produced by the $\varepsilon$-martensite, which is formed from the parent austenite (cf. Fig. 3). Consequently, the macroscopic texture in $\varepsilon$-martensite follows the transformation texture $\gamma \rightarrow \varepsilon$, which is controlled by the transformation work and by the Schmid factor of the partial dislocations $\frac{a}{6}\langle 121\rangle\{111\}$ in austenite, during the whole deformation process (Fig. 5).

During the $\varepsilon \rightarrow \alpha^{\prime}$ transformation, $\alpha$-martensite can form on the $(0001)_{\varepsilon}$ lattice planes of $\varepsilon$-martensite in six distinguishable (differently oriented) modifications related to the six crystallographically equivalent lattice planes $\{110\}_{\alpha}$, cf. Fig. $6 \mathrm{f}$ and Table 2 . As the symmetry operations along the directions $\langle 0001\rangle_{\varepsilon}$ and $\langle 110\rangle_{\alpha}$ are not matching (Fig. 3), the variants of $\alpha$-martensite, which are similarly favourable from the point of view of the transformation work, do not necessarily produce the macroscopic orientations of transformed $\alpha$-martensite corresponding to the transformation texture. The competition between the transformation texture obeying the Burgers orientation relationship and the variant selection of the $\varepsilon \rightarrow \alpha^{\prime}$ transformation following the transformation work is visible in the dependence of the macroscopic texture in $\alpha$-martensite on the applied load (Fig. 5). At low deformations, the $\{100\}$ texture in $\alpha$-martensite is dominated by the transformation texture as discussed in Section 3.4. At higher loads, additional $\alpha$-martensite variants with less favourable transformation work arise. These variants of $\alpha$-martensite do not necessarily comply with the initial transformation texture (Fig. 3). This effect is evidenced by the formation of twinned variants of $\alpha$-martensite (V2 in Fig. 6c), which compensate the shear strain induced by the volume expansion accompanying the phase transformation $\varepsilon \rightarrow \alpha^{\prime}$ $[55,65,90]$. As the total volume expansion increases with increasing $\alpha$-martensite fraction, other orientation variants of $\alpha$-martensite are generated in larger quantities at higher external loads, thus the degree of the macroscopic texture in $\alpha^{\prime}$-martensite deteriorates with increasing deformation (Fig. 5).
The interplay between the transformation texture controlled by the orientation relationship of consecutive phases, the number of possible orientation variants controlled by the crystal symmetries and the variant selection controlled by the transformation work is illustrated in Fig. 8. This figure shows the propagation of different grain orientations during the phase transformation $\gamma \rightarrow \varepsilon \rightarrow \alpha^{\prime}$. The first two panels depict orientations of the austenitic grains, which are oriented favourably (Fig. 8a) and unfavourably (Fig. 8b) to the external load from the point of view of the probability of the $\varepsilon$-martensite formation (cf. Fig. 7). Using the ShojiNishiyama orientation relationship, the austenite orientations from Fig. $8 \mathrm{a}$ and $\mathrm{b}$ were converted into the corresponding orientations of $\varepsilon$-martensite. Each orientation of austenite produced four orientations of $\varepsilon$-martensite, which form on one of the four crystallographically equivalent $\{111\}_{\gamma}$ lattice planes. The $\varepsilon$-martensite variant with the most negative transformation strain $\varepsilon_{z z}^{\gamma \rightarrow \varepsilon}$ is plotted in Fig. $8 \mathrm{c}$ and $\mathrm{d}$ in colour, the other variants are depicted by grey symbols. The shape of the symbols is kept the same for all orientations connected by the orientation relationship.

Although the orientations of the austenite grains used for this simulation were distributed almost randomly (Fig. $8 \mathrm{a}$ and b), the orientations of the $\varepsilon$-martensite variants with most favourable transformation work are concentrated around the reciprocal space direction $\{10 \overline{1} 3\}_{\varepsilon}$ (Fig. $8 \mathrm{c}$ and d). This means that every austenite grain (having an arbitrary orientation with respect to the applied load in the original state) will produce local hcp crystallites of $\varepsilon$-martensite with orientations, which are not far from $\{10 \overline{1} 3\}_{\varepsilon}$. Thus, the variant selection during the martensitic transformation $\gamma \rightarrow \varepsilon$ helps to strengthen the macroscopic texture in $\varepsilon$-martensite. Furthermore, the austenite orientations promoting the martensitic transformation (Fig. 8a) result in a stronger clustering of $\varepsilon$-martensite variants close to the reciprocal space direction $\{10 \overline{1} 3\}_{\varepsilon}$ (Fig. 8c). On the contrary, the deformation-induced preferred orientation $\{110\}_{\gamma}$ of austenite grains (Fig. 5c) counteracts the intensification of the $\varepsilon$-martensite texture, because the $\{110\}$-oriented austenite grains are unfavourable from the point of view of the $\gamma \rightarrow \varepsilon$ transformation (cf. Figs. 7 and 8 b). The formation of the $\{10 \overline{1} 3\}_{\varepsilon}$ texture (Fig. 2), whose degree is almost independent of the deformation state (Fig. 5b and c), is the result of the competition between a strong transformation texture and the evolving preferred orientation of austenite grains (Fig. 8a and b). The texture in austenite sharpens with increasing deformation (Fig. 1), but it reduces the tendency of austenite to transform to $\varepsilon$-martensite, in particular in $\{110\}$-textured austenite grains (Fig. 7).

In Fig. $8 \mathrm{e}$ and $\mathrm{f}$, the propagation of the grain orientations is shown for the $\varepsilon \rightarrow \alpha^{\prime}$ transformation. Analogously to the first transformation step $(\gamma \rightarrow \varepsilon)$, all possible $\alpha$-martensite orientation variants following the Burgers orientation relationship (Eq. 2) were reproduced. For each 

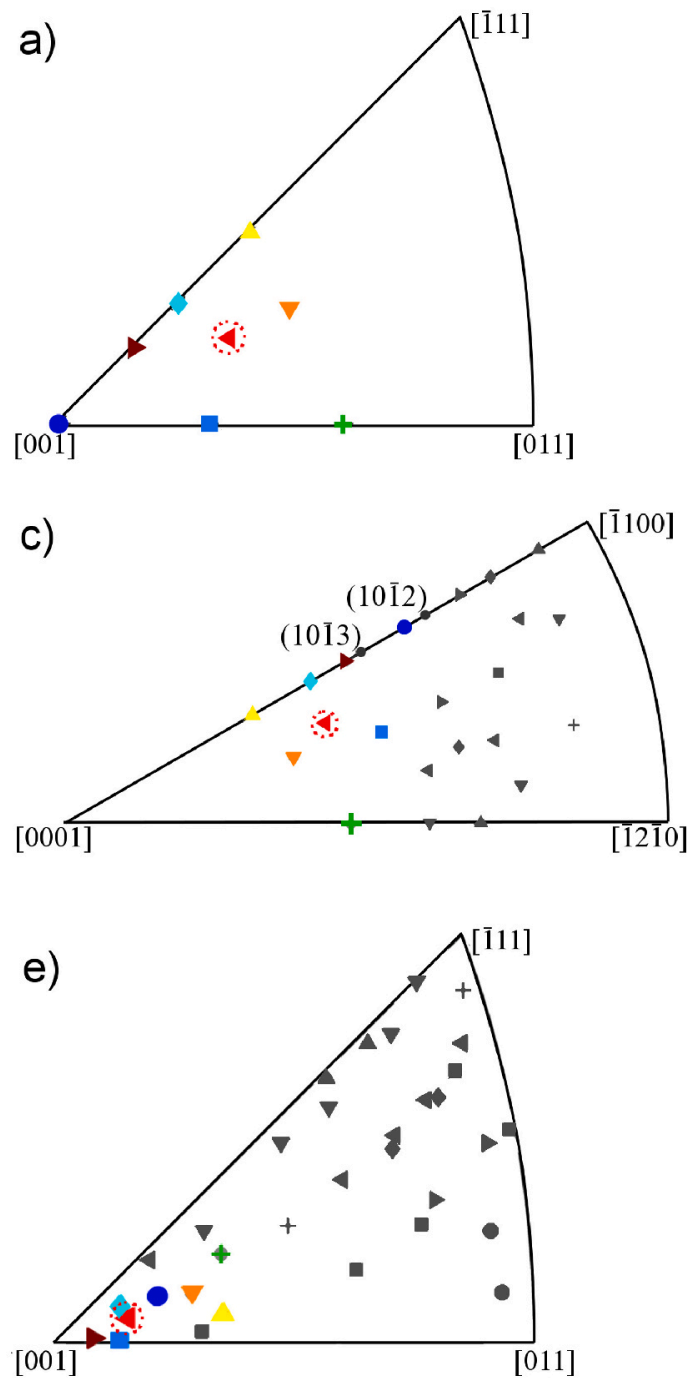
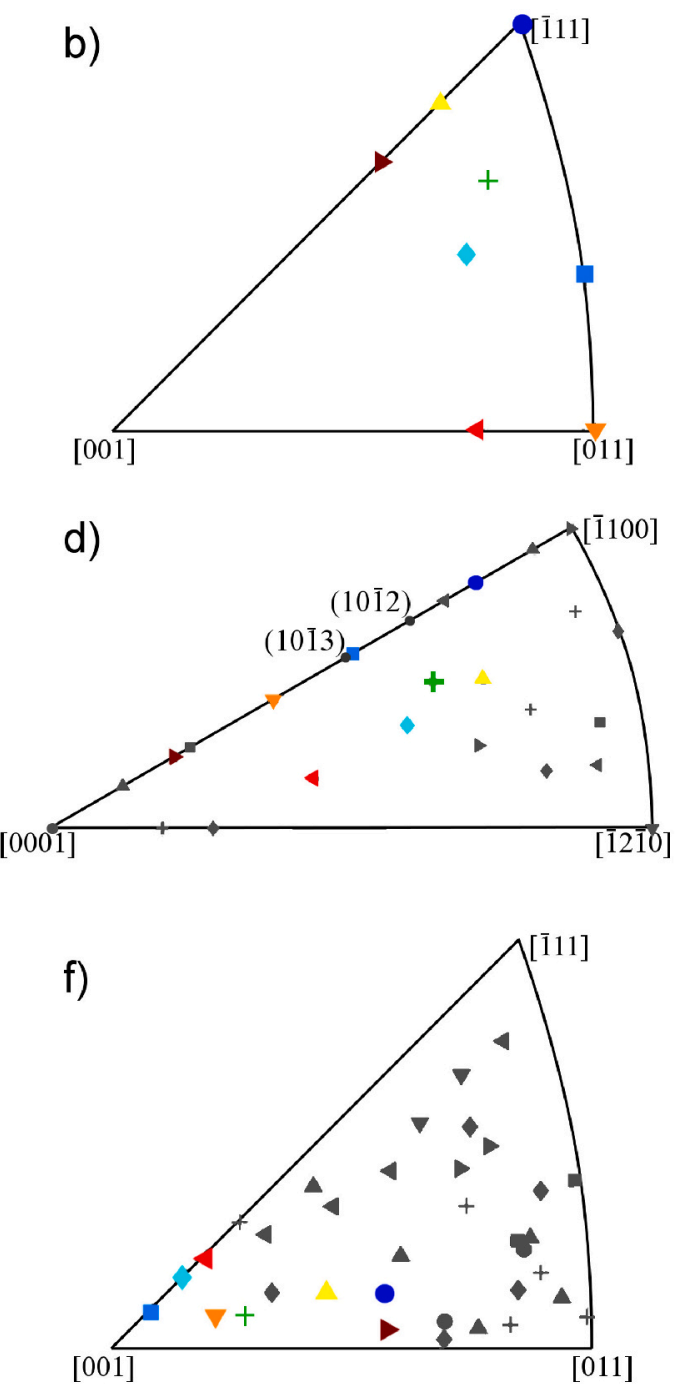

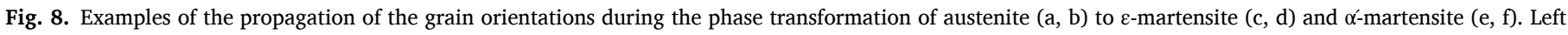

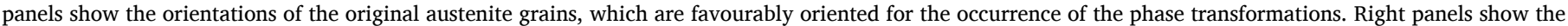

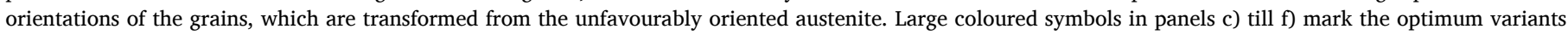

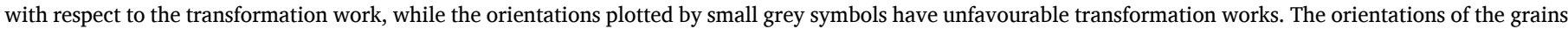

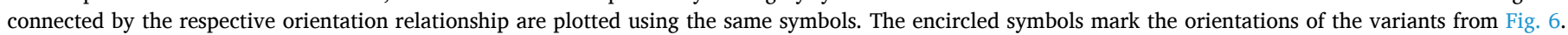

crystallographically equivalent set of the variants, the variant with the highest negative transformation work was highlighted in the inverse pole figure (Figs. $8 \mathrm{e}$ and $8 \mathrm{f}$ ) by colouring the respective symbols. For the favourable orientations of the original austenite (Fig. 8a), all highlighted $\alpha$-martensite variants (having low transformation work) accumulate near the reciprocal space direction $\{100\}_{\alpha^{\prime}}$, which is in a good agreement with the fibre texture $\{100\}_{\alpha^{\prime}}$ observed in $\alpha$-martensite (Fig. 4). This trend is supported also by the example shown in Fig. 6 .

Analogously to the $\gamma \rightarrow \varepsilon$ transformation, the favourable and the unfavourable orientations of parent austenite lead to the $\{100\}_{\alpha^{\prime}}$ texture after the $\gamma \rightarrow \varepsilon \rightarrow \alpha^{\prime}$ transformation (Fig. 8e and f). Still, also for the $\varepsilon \rightarrow$ $\alpha^{\prime}$ transformation, the martensite variants formed from favourable austenite orientations (Fig. 8e) cluster more tightly than the unfavourable ones (Fig. 8f), and the sharpening of the $\{110\}_{\gamma}$ texture in austenite retards the formation of $\alpha$-martensite via $\gamma \rightarrow \varepsilon \rightarrow \alpha^{\prime}$ transformation. From this point of view, the texture $\{100\}_{\alpha^{\prime}}$ in $\alpha$-martensite should be dominated by the phase transformation and the variant selection. This effect was observed at the beginning of the deformation process, where the amount of $\alpha$-martensite was low (Fig. 5). At larger amounts of $\alpha$-martensite in the highly deformed sample, however, the effect of the transformation texture competes against the formation of the $\alpha$-martensite variants, which have a high transformation work (Table 2), but compensate the volume expansion accompanying the $\varepsilon \rightarrow$ $\alpha^{\prime}$ transformation.

The example in Fig. $6 \mathrm{f}$ shows that the new $\alpha$-martensite variants are twin-related to the first ones. The typical twin planes $\{211\}$ in bcc metals $[88,92]$, switch the $\alpha$-martensite orientations close to $\{100\}_{\alpha}$, to the orientations close to $\{111\}_{\alpha}$, as it can be seen in Fig. $6 \mathrm{f}$ for the variant V2. This effect can also be illustrated on the stereographic projection in Fig. 3, where the trace of the twin plane $(1 \overline{1} 2)_{\alpha^{\prime}}$ intersects the poles $1 \overline{11}_{\alpha^{\prime}}, 110_{\alpha^{\prime}}$ and $\overline{1} 11_{\alpha^{\prime}}$. As the need for the compensation of the volume expansion grows with increasing fraction of $\alpha$-martensite (and with increasing external load), the intensity of the texture component $\{111\}_{\alpha}$ decreases much more slowly than the strength of the texture component $\{100\}_{\alpha^{\prime}}$ (Fig. 5b).

\section{Conclusions}

The in situ synchrotron radiation diffraction study carried out on a metastable austenitic steel under uniaxial compression revealed the information about the deformation-induced changes of the phase composition and about the associated development of the preferred 
orientation of crystallites in individual phases. With increasing deformation, the original austenite formed a progressively strengthening $\{110\}$ texture, and transformed to $\varepsilon$-martensite with a $\{10 \overline{1} 3\}$ texture and later to $\alpha$-martensite with mixed $\{100\} \&\{111\}$ texture. In contrast to the $\{10 \overline{1} 3\}$ texture of $\varepsilon$-martensite, whose degree stayed almost constant independent of the deformation degree, the preferred orientations of crystallites in $\alpha$-martensite deteriorated at higher deformations and thus at larger $\alpha$-martensite fraction. With the aid of the local orientation measurements using electron backscatter diffraction and with the aid of the description of the fundamental processes accompanying the martensitic phase transformations, the different deformation behaviour of the phases was explained by the competition of several, partly counteracting mechanisms. These are (i) the mechanisms of the martensitic transformation $\gamma \rightarrow \varepsilon$, i.e., the formation and wide dissociating of the partial dislocations and their dependence on the austenite orientation with respect to the applied load, (ii) the transformation texture, which is controlled by the respective orientation relationship between the consecutive phases, (iii) the variant selection following the beneficial transformation work and (iv) the formation of twinned orientations in $\alpha$-martensite that compensate the volume expansion during the $\varepsilon \rightarrow \alpha^{\prime}$ transformation.

The formation of the $\{110\}$ texture in austenite under uniaxial load is an intrinsic phenomenon. However, it is unfavourable for the stacking fault formation and, therefore, impedes the phase transformation $\gamma \rightarrow \varepsilon$ at higher deformations. The $\{10 \overline{1} 3\}$ texture in $\varepsilon$-martensite is a transformation texture, which results from the Shoji \& Nishiyama orientation relationship between $\varepsilon$-martensite and the austenite grains, which are favourably oriented with respect to the formation and widening of the partial dislocations that is the first step to the $\varepsilon$-martensite formation. The $\alpha$-martensite shows a strong transformation texture $\{100\}$ in early deformation stages. This texture results from the Burgers orientation relationship between $\alpha$-martensite and the parent $\varepsilon$-martensite. At higher deformations, additional variants of $\alpha$-martensite are created, which compensate the volume expansion caused by the $\varepsilon \rightarrow \alpha^{\prime}$ transformation, but promote the strengthening of the $\{111\}$ texture at the expense of the $\{100\}$ texture.

\section{Data availability}

The raw/processed data required to reproduce these findings cannot be shared at this time due to technical or time limitations.

\section{Declaration of Competing Interest}

The authors declare that they have no known competing financial interests or personal relationships that could have appeared to influence the work reported in this paper.

\section{Acknowledgements}

This work is based upon experiments performed at the HEMS beamline operated by HZG at PETRA III (DESY) Hamburg, Germany. This work was funded by the German Research Foundation (DFG) as part of a research project within the Collaborative Research Centre SFB 799, project number 54473466. The authors thank Mr. R. Prang for the SEM sample preparation.

\section{Appendix A. Supplementary data}

Supplementary data to this article can be found online at https://doi. org/10.1016/j.matchar.2021.111132.

\section{References}

[1] A. Weidner, K. Fischer, H. Biermann, Ultrafine-grained CrMnNi steels: Lueders phenomenon and texture inheritance, Mater. Sci. Eng. A 799 (2021) 140197, https://doi.org/10.1016/j.msea.2020.140197.

[2] O. Grässel, L. Krüger, G. Frommeyer, L.W. Meyer, High strength Fe-Mn-(Al, Si) TRIP/TWIP steels development - properties - application, Int. J. Plast. 16 (2000) 1391-1409, https://doi.org/10.1016/S0749-6419(00)00015-2.

[3] G. Frommeyer, U. Brüx, P. Neumann, Supra-ductile and high-strength manganese TRIP/TWIP steels for high energy absorption purposes, ISIJ Int. 43 (2003) 438-446, https://doi.org/10.2355/isijinternational.43.438.

[4] B.C. DeCooman, Y. Estrin, S.K. Kim, Twinning-induced plasticity (TWIP) steels, Acta Mater. 142 (2018) 283-362, https://doi.org/10.1016/j.actamat.2017.06.046.

[5] S. Wolf, S. Martin, L. Krüger, U. Martin, Constitutive modelling of the rate dependent flow stress of cast high-alloyed metastable austenitic TRIP/TWIP steel, Mater. Sci. Eng. A594 (2014) 72-81, https://doi.org/10.1016/j.msea.2013.11.041.

[6] L. Krüger, S. Wolf, S. Martin, U. Martin, A. Jahn, A. Weiß, P.R. Scheller, Strain rate dependent flow stress and energy absorption behaviour of cast CrMnNi TRIP/TWIP steels, Steel Res. Int. 82 (2011) 1087-1093, https://doi.org/10.1002/ srin.201100067.

[7] F. Lecroisey, A. Pineau, Martensitic transformations induced by plastic deformation in the Fe-Ni-Cr-C system, Metall. Trans. A. 3 (1972) 387-396, https://doi.org/ $10.1007 /$ BF02642042.

[8] L. Rémy, A. Pineau, Twinning and strain-induced F.C.C. - H.C.P. transformation in the Fe-Mn-Cr-C system, Mater. Sci. Eng. 28 (1977) 99-107, https://doi.org/ 10.1016/0025-5416(77)90093-3.

[9] S. Martin, C. Ullrich, D. Šimek, U. Martin, D. Rafaja, Stacking fault model of $\varepsilon$-martensite and its DIFFaX implementation, J. Appl. Crystallogr. 44 (2011) 779-787, https://doi.org/10.1107/S0021889811019558.

[10] L. Bracke, L. Kestens, J. Penning, Transformation mechanism of alpha-martensite in an austenitic Fe-Mn-C-N alloy, Scr. Mater. 57 (2007) 385-388, https://doi.org/ 10.1016/j.scriptamat.2007.05.003.

[11] J. Talonen, H. Hänninen, Formation of shear bands and strain-induced martensite during plastic deformation of metastable austenitic stainless steels, Acta Mater. 55 (2007) 6108-6118, https://doi.org/10.1016/j.actamat.2007.07.015.

[12] A.S. Hamada, L.P. Karjalainen, R.D.K. Misra, J. Talonen, Contribution of deformation mechanisms to strength and ductility in two Cr-Mn grade austenitic stainless steels, Mater. Sci. Eng. A559 (2013) 336-344, https://doi.org/10.1016/j. msea.2012.08.108.

[13] L. Rémy, Temperature variation of the intrinsic stacking fault energy of a high manganese austenitic steel, Acta Metall. 25 (1977) 173-179, https://doi.org/ 10.1016/0001-6160(77)90120-1.

[14] R.M. Latanision, A.W. Ruff, The temperature dependence of stacking fault energy in Fe-Cr-Ni alloys, Metall. Trans. A. 2 (1971) 505-509, https://doi.org/10.1007/ BF02663341.

[15] S. Martin, S. Wolf, U. Martin, L. Krüger, Influence of temperature on phase transformation and deformation mechanisms of cast CrMnNi-TRIP/TWIP steel, Solid State Phenom. 172-174 (2011) 172-177, https://doi.org/10.4028/www. scientific.net/SSP.172-174.172.

[16] S. Martin, S. Wolf, U. Martin, L. Krüger, D. Rafaja, Deformation mechanisms in austenitic TRIP/TWIP steel as a function of temperature, Metall. Mater. Trans. A 47 (2016) 49-58, https://doi.org/10.1007/s11661-014-2684-4.

[17] J.A. Venables, The martensite transformation in stainless steel, Philos. Mag. 7 (1962) 35-44, https://doi.org/10.1080/14786436208201856.

[18] A. Weidner, S. Martin, V. Klemm, U. Martin, H. Biermann, Stacking faults in highalloyed metastable austenitic cast steel observed by electron channelling contrast imaging, Scr. Mater. 64 (2011) 513-516, https://doi.org/10.1016/j. scriptamat.2010.11.028.

[19] D. Borisova, V. Klemm, S. Martin, S. Wolf, D. Rafaja, Microstructure defects contributing to the energy absorption in CrMnNi TRIP steels, Adv. Eng. Mater. 15 (2013) 571-582, https://doi.org/10.1002/adem.201200327.

[20] S. Martin, S. Wolf, S. Decker, L. Krüger, U. Martin, Deformation bands in high-alloy austenitic 16Cr6Mn6Ni TRIP steel: phase transformation and its consequences on strain hardening at room temperature, Steel Res. Int. 86 (2015) 1187-1196, https://doi.org/10.1002/srin.201500005.

[21] G.B. Olson, M. Cohen, A mechanism for the strain-induced nucleation of martensitic transformations, J. Less Common Met. 28 (1972) 107-118, https://doi. org/10.1016/0022-5088(72)90173-7.

[22] G.B. Olson, M. Cohen, A general mechanism of martensitic nucleation: Part III. Kinetics of martensitic nucleation, Metall. Trans. A. 7 (1976) 1915-1923, https:// doi.org/10.1007/BF02659824.

[23] S. Martin, C. Ullrich, D. Rafaja, Deformation of austenitic CrMnNi TRIP/TWIP steels: nature and role of the $\varepsilon$-martensite, Mater. Today: Proc. 2 (2015) S643-S646, https://doi.org/10.1016/j.matpr.2015.07.366.

[24] G. Meric de Bellefon, J.C. van Duysen, Tailoring plasticity of austenitic stainless steels for nuclear applications: review of mechanisms controlling plasticity of austenitic steels below $400^{\circ} \mathrm{C}$, J. Nucl. Mater. 475 (2016) 168-191, https://doi. org/10.1016/j.jnucmat.2016.04.015.

[25] Z. Nishiyama, Martensitic Transformation, Academic Press, New York, San Francisco, London, 1978.

[26] W.G. Burgers, On the process of transition of the cubic-body-centered modification into the hexagonal-close-packed modification of zirconium, Physica 1 (1934) 561-586, https://doi.org/10.1016/S0031-8914(34)80244-3.

[27] G. Kurdjumov, G. Sachs, Über den Mechanismus der Stahlhärtung, Z. Phys. 64 (1930) 325-334, https://doi.org/10.1007/BF01397346. 
[28] H.J. Bunge, Texture analysis in materials science, Butterworth (1982), https://doi. org/10.1016/C2013-0-11769-2.

[29] H. Hu, Texture of metals, Texture 1 (1974) 233-258, https://doi.org/10.1155/ TSM.1.233.

[30] K. Tao, D.W. Brown, S.C. Vogel, H. Choo, Texture evolution during strain-induced martensitic phase transformation in $304 \mathrm{~L}$ stainless steel at a cryogenic temperature, Metall. Mater. Trans. A 37 (2006) 3469-3475, https://doi.org/ 10.1007/s11661-006-1042-6.

[31] E. Cakmak, S.C. Vogel, H. Choo, Effect of martensitic phase transformation on the hardening behavior and texture evolution in a 304L stainless steel under compression at liquid nitrogen temperature, Mater. Sci. Eng. A589 (2014) 235-241, https://doi.org/10.1016/j.msea.2013.09.093.

[32] I.R. Souza Filho, M.J.R. Sandim, D. Ponge, H.R.Z. Sandim, D. Raabe, Strain hardening mechanisms during cold rolling of a high-Mn steel: interplay between submicron defects and microtexture, Mater. Sci. Eng. A 754 (2019) 636-649, https://doi.org/10.1016/j.msea.2019.03.116.

[33] S.M. Copley, B.H. Kear, The dependence of the width of a dissociated dislocation on dislocation velocity, Acta Metall. 16 (1968) 227-231, https://doi.org/10.1016/ 0001-6160(68)90118-1.

[34] I. Karaman, H. Sehitoglu, K. Gall, Y.I. Chumlyakov, H.J. Maier, Deformation of single crystal Hadfield steel by twinning and slip, Acta Mater. 48 (2000) 1345-1359, https://doi.org/10.1016/S1359-6454(99)00383-3.

[35] T. Iwamoto, T. Tsuta, Y. Tomita, Investigation on deformation mode dependence of strain-induced martensitic transformation in trip steels and modelling of transformation kinetics, Int. J. Mech. Sci. 40 (1998) 173-182, https://doi.org/ 10.1016/S0020-7403(97)00047-7.

[36] P. Yang, Q. Xie, L. Meng, H. Ding, Z. Tang, Dependence of deformation twinning on grain orientation in a high manganese steel, Scr. Mater. 55 (2006) 629-631, https://doi.org/10.1016/j.scriptamat.2006.06.004.

[37] D. Geissler, J. Freudenberger, A. Kauffmann, M. Krautz, H. Klauss, A. Voss, J. Eickemeyer, L. Schultz, Appearance of dislocation-mediated and twinninginduced plasticity in an engineering-grade FeMnNiCr alloy, Acta Mater. 59 (2011) 7711-7723, https://doi.org/10.1016/j.actamat.2011.08.040.

[38] R. Ueji, Y. Takagi, N. Tsuchida, K. Shinagawa, Y. Tanaka, T. Mizuguchi, Crystallographic orientation dependence of epsilon martensite transformation during tensile deformation of polycrystalline $30 \% \mathrm{Mn}$ austenitic steel, Mater. Sci. Eng. A576 (2013) 14-20, https://doi.org/10.1016/j.msea.2013.03.071.

[39] C. Ullrich, R. Eckner, L. Krüger, S. Martin, V. Klemm, D. Rafaja, Interplay of microstructure defects in austenitic steel with medium stacking fault energy, Mater. Sci. Eng. A649 (2016) 390-399, https://doi.org/10.1016/j. msea.2015.10.021.

[40] C. Donadille, R. Valle, P. Dervin, R. Penelle, Development of texture and microstructure during cold-rolling and annealing of F.C.C. alloys: example of an austenitic stainless steel, Acta Metall. 37 (1989) 1547-1571, https://doi.org/ 10.1016/0001-6160(89)90123-5.

[41] E. El-Danaf, S.R. Kalidindi, R.D. Doherty, C. Necker, Deformation texture transition in brass: critical role of micro-scale shear bands, Acta Mater. 48 (2000) 2665-2673, https://doi.org/10.1016/S1359-6454(00)00050-1.

[42] D. Barbier, N. Gey, S. Allain, N. Bozzolo, M. Humbert, Analysis of the tensile behavior of a TWIP steel based on the texture and microstructure evolutions, Mater. Sci. Eng. A500 (2009) 196-206, https://doi.org/10.1016/j. msea.2008.09.031.

[43] H. Beladi, I.B. Timokhina, Y. Estrin, J. Kim, B.C. DeCooman, S.K. Kim, Orientation dependence of twinning and strain hardening behaviour of a high manganese twinning induced plasticity steel with polycrystalline structure, Acta Mater. 59 (2011) 7787-7799, https://doi.org/10.1016/j.actamat.2011.08.031.

[44] M.X. Zhang, P.M. Kelly, J.D. Gates, A model of stress induced martensitic transformation in Fe-Ni-C alloy, Mater. Sci. Eng. A273-275 (1999) 251-256, https://doi.org/10.1016/S0921-5093(99)00349-4.

[45] K. Tao, J.J. Wall, H. Li, D.W. Brown, S.C. Vogel, H. Choo, In situ neutron diffraction study of grain-orientation-dependent phase transformation in $304 \mathrm{~L}$ stainless steel at a cryogenic temperature, J. Appl. Phys. 100 (2006) 1-7, https://doi.org/ 10.1063/1.2402474 (123515).

[46] E. Cakmak, H. Choo, K. An, Y. Ren, A synchrotron X-ray diffraction study on the phase transformation kinetics and texture evolution of a TRIP steel subjected to torsional loading, Acta Mater. 60 (2012) 6703-6713, https://doi.org/10.1016/j. actamat.2012.08.040.

[47] D.D. Ma, P. Yang, X.F. Gu, Y. Onuki, S. Sato, In-situ neutron diffraction investigation on the martensite transformation, texture evolution and martensite reversion in high manganese TRIP steel, Mater. Charact. 163 (2020) 110244, https://doi.org/10.1016/j.matchar.2020.110244.

[48] D. Raabe, Texture and microstructure evolution during cold rolling of a strip cas and of a hot rolled austenitic stainless steel, Acta Mater. 45 (1997) 1137-1151, https://doi.org/10.1016/S1359-6454(96)00222-4.

[49] B.R. Kumar, A.K. Singh, B. Mahato, P.K. De, N.R. Bandyopadhyay, D. K. Bhattacharya, Deformation-induced transformation textures in metastable austenitic stainless steel, Mater. Sci. Eng. A429 (2006) 205-211, https://doi.org/ 10.1016/j.msea.2006.05.107.

[50] I.R. Souza Filho, K.D. Zilnyk, M.J.R. Sandim, R.E. Bolmaro, H.R.Z. Sandim, Strain partitioning and texture evolution during cold rolling of AISI 201 austenitic stainless steel, Mater. Sci. Eng. A702 (2017) 161-172, https://doi.org/10.1016/j. msea.2017.07.010.

[51] D. Goodchild, W.T. Roberts, D.V. Wilson, Plastic deformation and phase transformation in textured austenitic stainless steel, Acta Metall. 18 (1970) 1137-1145, https://doi.org/10.1016/0001-6160(70)90104-5.
[52] J.Y. Kang, H. Kim, K.I. Kim, C.H. Lee, H.N. Han, K.H. Oh, T.H. Lee, Effect of austenitic texture on tensile behavior of lean duplex stainless steel with transformation induced plasticity (TRIP), Mater. Sci. Eng. A681 (2017) 114-120, https://doi.org/10.1016/j.msea.2016.11.001.

[53] M. Kato, T. Mori, Stress-induced martensite in single crystals of an Fe-23Ni-5Cr alloy, Acta Metall. 24 (1976) 853-860, https://doi.org/10.1016/0001-6160(76) 90052-3.

[54] P. Bate, B. Hutchinson, The effect of elastic interactions between displacive transformations on textures in steels, Acta Mater. 48 (2000) 3183-3192, https:// doi.org/10.1016/S1359-6454(00)00106-3.

[55] N. Gey, B. Petit, M. Humbert, Electron backscattered diffraction study of alpha/ epsilon martensitic variants induced by plastic deformation in 304 stainless steel, Metall. Mater. Trans. A 36 (2005) 3291-3299, https://doi.org/10.1007/s11661005-0003-9.

[56] M. Humbert, B. Petit, B. Bolle, N. Gey, Analysis of the gamma-epsilon-alpha' variant selection induced by $10 \%$ plastic deformation in 304 stainless steel at -60 ${ }^{\circ}$ C, Mater. Sci. Eng. A454-455 (2007) 508-517, https://doi.org/10.1016/j. msea.2006.11.112.

[57] B. Petit, N. Gey, M. Cherkaoui, B. Bolle, M. Humbert, Deformation behavior and microstructure/texture evolution of an annealed 304 AISI stainless steel sheet. experimental and micromechanical modeling, Int. J. Plast. 23 (2007) 323-341, https://doi.org/10.1016/j.ijplas.2006.07.002.

[58] Y. Kim, T.H. Ahn, D.W. Suh, H.N. Han, Variant selection during mechanically induced martensitic transformation of metastable austenite by nanoindentation, Scr. Mater. 104 (2015) 13-16, https://doi.org/10.1016/j.scriptamat.2015.03.014.

[59] T. Tomida, Variant selection mechanism by elastic anisotropy and double K-S relation for transformation texture in steel; difference between martensite and ferrite, Acta Mater. 146 (2018) 25-41, https://doi.org/10.1016/j. actamat.2017.12.033.

[60] H. Wang, Y. Jeong, B. Clausen, Y. Liu, R.J. McCabe, F. Barlat, C.N. Tomé, Effect of martensitic phase transformation on the behavior of 304 austenitic stainless steel under tension, Mater. Sci. Eng. A649 (2016) 174-183, https://doi.org/10.1016/j. msea.2015.09.108.

[61] M. Benke, A. Hlavacs, E. Nagy, G. Karacs, V. Mertinger, The effect of variant selection on texture of TWIP/TRIP steels during uniaxial tensile loading, Metall. Mater. Trans. A A51 (2020) 1519-1527, https://doi.org/10.1007/s11661-02005664-w.

[62] S. Morito, H. Tanaka, R. Konishi, T. Furuhara, T. Maki, The morphology and crystallography of lath martensite in Fe-C alloys, Acta Mater. 51 (2003) 1789-1799, https://doi.org/10.1016/S1359-6454(02)00577-3.

[63] Y. Tian, U. Lienert, A. Borgenstam, T. Fischer, P. Hedström, Martensite formation during incremental cooling of Fe-Cr-Ni alloys: An in-situ bulk X-ray study of the grain-averaged and single-grain behavior, Scr. Mater. 136 (2017) 124-127, https://doi.org/10.1016/j.scriptamat.2017.04.020.

[64] J.R. Patel, M. Cohen, Criterion for the action of applied stress in the martensitic transformation, Acta Metall. 1 (1953) 531-538, https://doi.org/10.1016/00016160(53)90083-2.

[65] N. Li, Y.D. Wang, W.J. Liu, Z.N. An, J.P. Liu, R. Su, J. Li, P.K. Liaw, In situ X-ray microdiffraction study of deformation-induced phase transformation in 304 austenitic stainless steel, Acta Mater. 64 (2014) 12-23, https://doi.org/10.1016/j. actamat.2013.11.001.

[66] Y. Tian, S. Lin, J.Y. Peter Ko, U. Lienert, A. Borgenstam, P. Hedström, Micromechanics and microstructure evolution during in situ uniaxial tensile loading of TRIP-assisted duplex stainless steels, Mater. Sci. Eng. A 734 (2018) 281-290, https://doi.org/10.1016/j.msea.2018.07.040.

[67] C. Ullrich, S. Martin, C. Schimpf, A. Stark, N. Schell, D. Rafaja, Deformation mechanisms in metastable austenitic TRIP/TWIP steels under compressive load studied by in situ synchrotron radiation diffraction, Adv. Eng. Mater. 21 (2019) 1801101, https://doi.org/10.1002/adem.201801101.

[68] H. Naser, F. De Geuser, M. Mantel, M. Véron, A. Deschamps, Macro and micro mechanical in-situ characterization using synchrotron diffraction of architectured micro-composite duplex stainless steels, Mater. Sci. Eng. A 793 (2020) 139852, https://doi.org/10.1016/j.msea.2020.139852.

[69] H. Choo, M.R. Koehler, L.P. White, Y. Ren, D. Morin, E. Garlea, Influence of defect characteristics on tensile deformation of an additively manufactured stainless steel: evolutions of texture and intergranular strain, Mater. Sci. Eng. A 791 (2020) 139637, https://doi.org/10.1016/j.msea.2020.139637.

[70] J. Macchi, S. Gaudez, G. Geandier, J. Teixeira, S. Denis, F. Bonnet, S.Y.P. Allain, Dislocation densities in a low-carbon steel during martensite transformation determined by in situ high energy X-ray diffraction, Mater. Sci. Eng. A 800 (2021) 140249, https://doi.org/10.1016/j.msea.2020.140249.

[71] I.R. Souza Filho, A. Dutta, D.R. Almeida Junior, W. Lu, M.J.R. Sandim, D. Ponge, H. R.Z. Sandim, D. Raabe, The impact of grain-scale strain localization on strain hardening of a high-Mn steel: real-time tracking of the transition from the $\gamma \rightarrow \varepsilon \rightarrow$ $\alpha^{\prime}$ transformation to twinning, Acta Mater. 197 (2020) 123-136, https://doi.org/ 10.1016/j.actamat.2020.07.038.

[72] E. Polatidis, G.N. Haidemenopoulos, D. Krizan, N. Aravas, T. Panzner, M. Šmíd, I. Papadioti, N. Casati, S. Van Petegem, H. Van Swygenhoven, The effect of stress triaxiality on the phase transformation in transformation induced plasticity steels: experimental investigation and modelling the transformation kinetics, Mater. Sci. Eng. A 800 (2021) 140321, https://doi.org/10.1016/j.msea.2020.140321.

[73] D. Rafaja, C. Krbetschek, C. Ullrich, S. Martin, Stacking fault energy in austenitic steels determined by using in situ X-ray diffraction during bending, J. Appl. Crystallogr. 47 (2014) 936-947, https://doi.org/10.1107/S1600576714007109. 
[74] H.R. Wenk, S. Grigull, Synchrotron texture analysis with area detectors, J. Appl. Crystallogr. 36 (2003) 1040-1049, https://doi.org/10.1107/ S0021889803010136.

[75] S. Matthies, G.W. Vinel, On the reproduction of the orientation distribution function of texturized samples from reduced pole figures using the conception of a conditional ghost correction, Phys. Status Solidi B 112 (1982) K111-K114, https:// doi.org/10.1002/pssb.2221120254.

[76] L. Lutterotti, S. Matthies, H.R. Wenk, MAUD, A friendly Java program for materia analysis using diffraction, IUCr Commission Powder Diffrac. Newslett. 21 (1999) $14-15$.

[77] L. Lutterotti, D. Chateigner, S. Ferrari, J. Ricote, Texture, residual stress and structural analysis of thin films using a combined X-ray analysis, Thin Solid Films 450 (2004) 34-41, https://doi.org/10.1016/j.tsf.2003.10.150.

[78] L. Lutterotti, R. Vasin, H.R. Wenk, Rietveld texture analysis from synchrotron diffraction images. I. Calibration and basic analysis, Powder Diffract. 29 (2014) 76-84, https://doi.org/10.1017/S0885715613001346.

[79] D. Canelo-Yubero, G. Requena, F. Sket, C. Poletti, F. Warchomicka, J. Daniels, N. Schell, A. Stark, Load partition and microstructural evolution during in situ hot deformation of Ti-6Al-6V-2Sn alloys, Mater. Sci. Eng. A657 (2016) 244-256, https://doi.org/10.1016/j.msea.2016.01.059.

[80] H.R. Wenk, L. Lutterotti, P. Kaercher, W. Kanitpanyacharoen, L. Miyagi, R. Vasin, Rietveld texture analysis from synchrotron diffraction images. II. Complex multiphase materials and diamond anvil cell experiments, Powder Diffract. 29 (2014) 220-232, https://doi.org/10.1017/S0885715614000360.

[81] A.P. Hammersley, ESRF Internal Report, ESRF97HA02T, FIT2D: An Introduction and Overview, ESRF, Grenoble, France, 1997.

[82] R. Hielscher, H. Schaeben, A novel pole figure inversion method: specification of the MTEX algorithm, J. Appl. Crystallogr. 41 (2008) 1024-1037, https://doi.org/ $10.1107 /$ S0021889808030112.
[83] F. Bachmann, R. Hielscher, H. Schaeben, Texture analysis with MTEX - free and open source software toolbox, Solid State Phenom. 160 (2010) 63-68, https://doi. org/10.4028/www.scientific.net/SSP.160.63.

[84] E.A. Calnan, C.J.B. Clews, Deformation textures in face-centred cubic metals, Lond. Edinb. Phil. Mag. 7 (1950) 1085-1100, https://doi.org/10.1080/ 14786445008561151.

[85] A.D. Rollett, S.I. Wright, Typical textures in metals, in: U.F. Kocks, C.N. Tomé, H. R. Wenk (Eds.), Texture and Anisotropy: Preferred Orientations in Polycrystals and their Effect on Materials Properties, Cambridge University Press, Edinburgh Building, Cambridge, UK, 1998, pp. 178-238.

[86] A. Creuziger, C.A. Calhoun, W.A. Poling, T. Gnäupel-Herold, Assessment of bias errors caused by texture and sampling methods in diffraction-based steel phase measurements, J. Appl. Crystallogr. 51 (2018) 720-731, https://doi.org/10.1107/ S160057671800420X.

[87] T.S. Byun, On the stress dependence of partial dislocation separation and deformation microstructure in austenitic stainless steels, Acta Mater. 51 (2003) 3063-3071, https://doi.org/10.1016/S1359-6454(03)00117-4.

[88] J.S. Bowles, J.K. Mackenzie, The crystallography of martensite transformations I, Acta Metall. 2 (1954) 129-137, https://doi.org/10.1016/0001-6160(54)90102-9.

[89] J.F. Nye, Physical Properties of Crystals. Their Representation by Tensors and Matrices, Oxford University Press, 1985.

[90] H. Schumann, Kristallgeometrie, VEB Deutscher Verlag für Grundstoffindustrie, Leipzig, 1979.

[91] Y. Higo, F. Lecroisey, T. Mori, Relation between applied stress and orientation relationship of alpha' martensite in stainless steel single crystals, Acta Metall. 22 (1974) 313-323, https://doi.org/10.1016/0001-6160(74)90170-9.

[92] J.W. Christian, S. Mahajan, Deformation twinning, Prog. Mater. Sci. 39 (1995) 1-157, https://doi.org/10.1016/0079-6425(94)00007-7. 